\title{
1 SVEP1, a novel human coronary artery disease locus, promotes atherosclerosis
}

3 In-Hyuk Jung ${ }^{1 \dagger}$, Jared S. Elenbaas ${ }^{1 \dagger}$, Arturo Alisio ${ }^{1}$, Katherine Santana ${ }^{1}$, Erica P. Young ${ }^{1,2}$, Chul Joo

4 Kang $^{2}$, Puja Kachroo ${ }^{3}$, Kory J. Lavine ${ }^{1}$, Babak Razani ${ }^{1,4}$, Robert P. Mecham ${ }^{5}$, Nathan O. Stitziel ${ }^{1,2,6^{*}}$

$6{ }^{1}$ Center for Cardiovascular Research, Division of Cardiology, Department of Medicine, Washington 7 University School of Medicine, Saint Louis, MO, USA.

$8 \quad{ }^{2}$ McDonnell Genome Institute, Washington University School of Medicine, Saint Louis, MO, USA

$9{ }^{3}$ Division of Cardiothoracic Surgery, Department of Surgery, Washington University School of Medicine, 10 Saint Louis, MO, USA.

$11{ }^{4}$ Department of Pathology and Immunology, Washington University School of Medicine, Saint Louis, 12 MO, USA

$13{ }^{5}$ Department of Cell Biology and Physiology, Washington University School of Medicine, Saint Louis, 14 MO, USA

$15{ }^{6}$ Department of Genetics, Washington University School of Medicine, Saint Louis, MO, USA

18 †These authors contributed equally: In-Hyuk Jung, Jared Elenbaas

$19{ }^{*}$ Correspondence should be addressed to Nathan O. Stitziel. (e-mail: nstitziel@wustl.edu) 


\section{Summary}

29 A low-frequency variant of SVEP1, an extracellular matrix protein, is associated with risk of coronary

30 disease in humans independent of plasma lipids. Despite a robust statistical association, however, it was

31 unclear if and how SVEP1 might contribute to atherosclerosis. Here, using Mendelian randomization

32 and complementary mouse models, we provide evidence that SVEP1 promotes atherosclerosis in

33 humans and mice. We find that SVEP1 is expressed by vascular smooth muscle cells (VSMCs) within

34 the atherosclerotic plaque. VSMCs also interact with SVEP1, causing proliferation and dysregulation of

35 key differentiation pathways, including integrin and Notch signaling. Fibroblast growth factor receptor

36 transcription increases in VSMCs interacting with SVEP1, and is further increased by the coronary

37 disease-associated SVEP1 variant. These effects ultimately drive inflammation and promote

38 atherosclerosis. Taken together, our results suggest that VSMC-derived SVEP1 is a pro-atherogenic

39 factor, and support the concept that pharmacological inhibition of SVEP1 should protect against

40 atherosclerosis in humans. 


\section{Introduction}

Cardiometabolic diseases are leading causes of morbidity and mortality and their prevalence is increasing (Dzau et al., 2002; Hansson and Klareskog, 2011; Liu and Ntambi, 2009; Rader and FitzGerald, 1998; Randolph, 2013; Ross, 1996; Virella and Lopes-Virella, 2003; Weber and Noels, 2011). Although approved treatments can help ameliorate these diseases, residual disease risk remains a substantial problem. Statin medications, for example, lower plasma cholesterol levels and reduce risk of coronary events by $20-30 \%$ (C Baigent, 2005), highlighting both significant residual risk and an unmet need for identifying alternative treatment strategies. Human genetics is a powerful approach to uncover potential therapeutic targets and to date more than 160 loci (Deloukas et al., 2013; Nelson et al., 2017; Nikpay et al., 2015; Schunkert et al., 2011) have been robustly associated with coronary artery disease (CAD). At most loci, however, the causal gene is unknown, presenting a major bottle-neck and hindering the translation of these findings into new therapies. We previously performed a large-scale exome-wide association study of low-frequency protein altering variation and identified a highly conserved missense polymorphism in SVEP1 (p.D2702G) that associated with an increased risk of CAD (Odds Ratio 1.14 per risk allele) (Stitziel et al., 2016). This CAD risk variant (hereto referred to as SVEP1 ${ }^{\text {CADrv }}$ ) is not associated with an effect on plasma lipids but has a modest positive association with blood pressure and type 2 diabetes (Stitziel et al., 2016), suggesting this variant may broadly contribute to the progression of cardiometabolic disease.

SVEP1, also known as polydom, encodes a large extracellular matrix protein with sushi (complement control protein), von Willebrand factor type A, epidermal growth factor-like (EGF), and pentraxin domains (Gilges et al., 2000; Shur et al., 2006). This gene was originally discovered in a screen for Notch-interacting proteins, as it contains Notch-like repeat EGF-domains (Shur et al., 2006). The only protein currently known to directly interact with SVEP1 is integrin $\alpha 9 \beta 1$ (Sato-Nishiuchi et al., 2012), a provisional matrix-binding integrin that is also linked to increased blood pressure in humans(Levy et al., 2009; Takeuchi et al., 2010). Integrin $\alpha 9 \beta 1$ binds to the same protein domain that associated mechanisms were unclear. Here, we sought to determine if and how SVEP1 may influence harbors the variant residue in SVEP1 ${ }^{\text {CADrv }}$ (Sato-Nishiuchi et al., 2012) and both proteins also play critical roles in development, including lymphatic patterning (Karpanen et al., 2017; Samuelov et al., 2017). the development of atherosclerosis. Given the overlapping disease associations between SVEP1 and integrin $\alpha 9 \beta 1$, their shared biological functions, and the proximity of the variant to integrin $\alpha 9 \beta 1$ 's 
binding site, we focused our mechanistic studies on cell types that play a prominent role in atherosclerosis and express SVEP1 and/or integrin $\alpha 9 \beta 1$.

\section{Results}

\section{SVEP1 is expressed by arterial VSMCs under pathological conditions.}

To begin characterizing the role of SVEP1 in the pathogenesis of atherosclerosis, we sought to identify disease-relevant tissues and cell types that express SVEP1. Expression data from the GenotypeTissue Expression (GTEx) project indicate that human arterial tissue, including coronary arteries, express SVEP1 (Figure S1A). To confirm arterial expression, we used in situ hybridization on tissue explants from the aortic wall and internal mammary artery of patients with established coronary artery disease. SVEP1 expression was readily detected within cells staining with the vascular smooth muscle cell marker, smooth muscle $\alpha$-actin (SM $\alpha$-actin) (Figure 1A). VSMCs are known to increase synthesis of certain extracellular matrix proteins in response to various pathological stimuli (Cangemi et al., 2011); therefore, we assessed expression data from relevant disease specimens to determine if this also applies to SVEP1. Indeed, SVEP1 expression is higher within human atherosclerotic tissue from carotid explants, relative to patient-paired adjacent and macroscopically intact tissue (Ayari and Bricca, 2013) (Figure S1B). Athero-prone arterial tissue explants from patients with diabetes also express higher levels of SVEP1 compared to patients without diabetes (Cangemi et al., 2011) (Figure S1C).

We obtained mice expressing a lacZ reporter under the native Svep1 promotor to determine whether murine Svepl expression recapitulated human SVEP1 expression, and may therefore be a viable animal model to study its effects on disease. Within healthy arterial tissue of young mice, we observed low $\beta$-gal expression, mostly colocalizing with VSMCs (Figure 1B). These data are consistent with published single-cell studies that identify VSMCs within the healthy murine aorta as a minor source of Svepl expression (Kalluri et al., 2019) (Figure S1D). To determine if murine Svepl expression was increased in the development of atherosclerosis, as in humans, we assayed expression within mouse arterial tissue after the induction of atherosclerosis. Experimental atherosclerosis was induced by feeding atheroprone $\left(\right.$ Apoe $\left.^{-/}\right)$mice a Western, high-fat diet (HFD) for 8 weeks. Apoe ${ }^{-/}$mice fed a standard chow diet (CD) served as non-atherogenic controls. After 8 weeks of an atherogenic HFD, we observed a 2-fold increase in Svep1 expression relative to CD fed control mice (Figure 1C, S1E). This expression was colocalized with neointimal cells that co-stained with SM $\alpha$-actin, suggesting VSMC expression (Figure 1C). 
Numerous cell types have been demonstrated to gain expression of VSMC markers in the context of atherosclerosis (Bennett et al., 2016). Therefore, to test the hypothesis that VSMC-derived cells within the neointima are the predominate source of Svep1, we generated Apoe ${ }^{-/}$mice with VSMC-

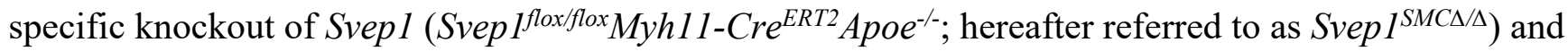

117 mice with unaltered Svep1 expression $\left(\right.$ Svep $1^{+/+} M_{y h 11-C r e}{ }^{E R T 2} A p o e^{-/}$; hereafter referred to as

118 Svep $1^{S M C+/+}$ ), which served as controls. Svepl expression was assessed using in situ hybridization

119 within the neointima of the aortic root of both groups after 8 weeks of HFD feeding. Indeed, while we 120 observed robust Svep1 expression in control mice, neointimal Svepl expression was nearly undetectable 121 in Svep ${ }^{S M C \Delta / \Delta}$ mice (Figure 1D, S1F). These data indicate that VSMC-derived cells are the major source 122 of Svepl in atherosclerotic plaque.

123 Given the increased expression of Svep1 under atherosclerotic conditions in mice and humans, 124 we tested the ability of atheroma-associated oxidized LDL (oxLDL) to directly induce Svep 1 expression 125 in VSMCs. Exposure to oxLDL increased Svep1 expression by 48\% in primary VSMCs from 126 Svep $1^{S M C+/+}$ mice but not Svep $1^{S M C \Delta / \Delta}$ mice, compared to vehicle-treated control cells (Figure 1E). Both 127 Svep $1^{S M C+/+}$ and Svep $1^{S M C \Delta / \Delta}$ cells increased expression of $C D 36$, indicating they were activated upon 128 binding of oxLDL with its receptor (Wei Li, 2010).

129 Taken together, these data demonstrate that SVEP1 is produced locally by VSMCs in 130 atherosclerotic disease and are consistent with prior studies suggesting SVEP1 is expressed by cells of 131 mesenchymal origin (Karpanen et al., 2017; Morooka et al., 2017). Further, these data suggest that 132 SVEP1 may play a direct role in the pathogenesis of atherosclerosis and that mouse models are an 133 appropriate means to interrogate this question.

\section{Svep1 drives atherosclerotic plaque development}

To study the effect of Svepl on atherosclerosis, we fed Apoe ${ }^{-/}$and Svep $1^{+/-}$Apoe $^{-/-}$mice (mice with homozygous Svep1 deficiency die from edema at day E18.5 (Karpanen et al., 2017; Morooka et al., 2017) a HFD for 8 weeks and analyzed the resulting atherosclerotic plaque burden. There were no observed differences between genotypes in body weight, plasma total cholesterol, triglycerides, and glucose (Figure 2A, B). Relative to controls, however, Svep $1^{+/-}$Apoe $^{-/}$mice had a significant reduction in plaque burden (as characterized by the percentage of surface area staining positive with Oil Red O) in the aortic arch and whole aorta by en face preparations, as well as in sectioned aortic roots (Figure 2C, D). Svepl deficiency also resulted in reduced macrophage staining within the aortic root neointima, as determined by the percentage of area staining positive for Mac3 (Figure 2E). We did not appreciate 
marked differences in measures of plaque stability, such as area staining positive for VSMC markers or necrotic core size, although collagen content was modestly higher in atheromas from control mice compared to Svep $1^{+/-}$Apoe $^{-/-}$mice (Figure S2A-C).

We then tested the hypothesis that the atherogenic effects of Svep1 could be attributed to its synthesis by VSMCs using Svep $1^{S M C \Delta / \Delta}$ and Svep $1^{S M C+/+}$ mice, as previously described. As with Svep1 haploinsufficiency, loss of Svep1 in VSMCs did not significantly alter body weight, plasma cholesterol, triglycerides and glucose levels (Figure 3A, B) following 8 weeks of HFD feeding. Also consistent with our Svepl haploinsufficiency model, Svep $1^{S M C \Delta / \Delta}$ mice had decreased plaque burden plaque in the aortic arch, whole aorta, and aortic root (Figure $3 \mathrm{C}, \mathrm{D})$, as compared to Svep $1^{S M C+/+}$ control mice. Additionally, atheromas from Svep $1^{S M C \Delta / \Delta}$ mice contained less macrophage staining and necrotic core area, indicators of plaque instability, and unaltered collagen content (Figure S3A-C).

Given the observations that loss of Svep1 in VSMCs resulted in a dramatic reduction in plaque size in the setting of 8 weeks HFD feeding, we extended the length of plaque development to investigate the effect of Svepl on advanced plaque lesions. After treatment with tamoxifen, Svep1 ${ }^{\text {SMC+/+}}$ and Svep $1^{S M C \Delta / \Delta}$ mice were fed HFD for 16 weeks. Again, no differences were observed in body weight (Figure S3D), plasma cholesterol, and glucose levels (Figure S3E) between groups. Triglycerides were higher in the Svep $1^{S M C \Delta / \Delta}$ mice at a level of nominal significance $(P=0.046)$, but this was not observed at other timepoints or in the haploinsufficiency model. Although we did not detect a statistically significant effect of VSMC-specific Svep1 deletion on atherosclerotic plaque burden (Figure S3F, G), plaques from Svep $1^{S M C \Delta / \Delta}$ mice tended to be smaller and were both less complex and more stable than controls. These indicators of an altered plaque phenotype include decreased neointimal macrophage staining (Figure 3E) and necrotic core size (Figure 3F), in addition to greater collagen content (Figure $3 \mathrm{G})$. Taken together, these experimental atherosclerosis data suggest that Svep1 drives atherosclerosis and increases plaque complexity.

\section{SVEP1 is causally related to cardiometabolic disease in humans}

Due to the relationship we discovered between Svep1 depletion and reduced atherosclerosis across our mouse models, we wondered if the human SVEP1 CAD-associated D2072G missense polymorphism was associated with altered SVEP1 levels in humans. While we did not find that this allele (or other alleles in linkage disequilibrium) were associated with mRNA levels in GTEx (Figure S4A), we did find that the $2702 \mathrm{G}$ risk variant (SVEP1 ${ }^{\text {CADrv}}$ ) was associated with a significant increase in circulating plasma SVEP1 protein levels $\left(P=8 \times 10^{-14}\right.$; Figure 4A) as measured by two independent 
aptamers (Figure S4B) from participants in the INTERVAL study (Sun et al., 2018), suggesting that increased SVEP1 protein levels were associated with increased risk of CAD. We next wondered if this was true for other genetic variants influencing SVEP1 protein levels. Using published data from the INTERVAL study (Sun et al., 2018), we cataloged cis-acting variants that associated with SVEP1 protein levels at a genome-wide $\left(P<5 \times 10^{-8}\right)$ level of statistical significance (Figure 4B). We performed Mendelian Randomization (Burgess et al., 2015) using a subset of these variants in linkage equilibrium $\left(\mathrm{r}^{2}<0.3\right)$ and found that increased SVEP1 protein levels were causally related to increased CAD risk $\left(P=7 \times 10^{-11}\right.$; Figure 4C, D). We also asked if SVEP1 protein levels were causally related to increased risk for hypertension and type 2 diabetes due to the prior associations we observed for the SVEP1 ${ }^{\text {CADrv }}$ allele with these risk factors. Indeed, we found that increased SVEP1 protein levels were causally related to both hypertension $\left(P=2 \times 10^{-15}\right.$; Figure S4D) and type 2 diabetes $(P=0.0004$; Figure S4E).

To investigate how the human SVEP1 ${ }^{\text {CADrv }}$ missense polymorphism might impact CAD risk, we generated homozygous mice harboring the human SVEP $1^{\mathrm{CADrv}}$ at the orthologous murine position (Svep 1 2699G/2699G; hereafter referred to as Svep ${ }^{G / G}$ ). These mice were bred with Apoe $^{-/-}$mice to generate Svep $1^{G / G}$ Apoe ${ }^{-/-}$mice. We were not able to detect differences in body weight, serum total cholesterol, triglycerides, and glucose (Figure S4E-H) between groups after feeding HFD. We also did not appreciate a significant difference between groups in the development of atherosclerotic plaque at either 8 or 16 weeks of HFD feeding (Figure S4I, J). Although our prior human genetic study revealed a significant association with an increased risk of CAD, the effect of the SVEP1 ${ }^{\text {CADrv }}$ in humans was modest, in which each copy of the $\mathrm{G}$ allele was associated with a $14 \%$ increased risk of disease. If an effect size in mice is similarly modest, further investigation would require a very large number of animals, presenting both pragmatic and ethical barriers. To circumvent these concerns, subsequent

\section{VSMCs express integrin $\alpha 9 \beta 1$} identify receptors and associated cell types that interact with SVEP1 in the extracellular space. Integrin $\alpha 9 \beta 1$ is the only protein known to interact with Svep1 and they colocalize in vivo (Sato-Nishiuchi et al., 2012). Integrins are transmembrane, heterodimeric receptors that respond to the extracellular environment and influence numerous aspects of atherosclerosis (Misra et al., 2018; Weng et al., 2003). Therefore, we hypothesized that integrin $\alpha 9 \beta 1$ (and associated cell-types) may be involved in Svep1- 
mediated atherosclerosis. ITGA9 is known to exclusively heterodimerize with ITGB1, therefore assessing ITGA9 expression is a reliable proxy for integrin $\alpha 9 \beta 1$ expression. Integrin $\alpha 9 \beta 1$ expression has been documented in airway epithelium, smooth muscle, skeletal muscle, hepatocytes, and epithelial cells (Chen et al., 2012; Danussi et al., 2011; Gupta and Vlahakis, 2010; Kanayama et al., 2009; Mostovich et al., 2011; Roy et al., 2011; Sato-Nishiuchi et al., 2012; Schreiber et al., 2009), yet arterial tissue expresses the highest ITGA9 levels of all GTEx tissues (Figure S5A). In situ hybridization confirmed that ITGA9 is broadly expressed in the human aortic wall and LIMA, predominately colocalizing with VSMCs (Figure 5A). Likewise, VSMCs of the murine aorta expressed high levels of $\operatorname{Itg} \alpha 9$ (Figure 5B). Consistent with these data, single cell studies of the murine aorta indicate the VSMCs express Itg $\alpha 9$ (Figure S5B) (Kalluri et al., 2019). Given the established role of VSMCs in CAD (Bennett et al., 2016), their expression of integrin $\alpha 9 \beta 1$, and the local expression patterns of Svep1 in disease, we tested the hypothesis that VSMCs respond to Svep1 in a cell-autonomous manner to promote atherosclerosis.

\section{Svep1 induces proliferation and integrin signaling in VSMCs}

The ECM plays a critical role in orchestrating cellular responses to tissue injury, including promoting cell proliferation and differentiation (Bennett et al., 2016; Johnson, 2014). We therefore assessed the proliferation of neointimal Svep $1^{S M C \Delta / \Delta}$ and Svep $1^{S M C+/+}$ VSMCs using immunofluorescent staining of the proliferation marker, mini-chromosome maintenance protein-2 (MCM-2). Among cells expressing smooth muscle actin, fewer stained positive for MCM-2 in Svep $1^{S M C \Delta / \Delta}$ mice as compared to Svep $1^{S M C+/+}$ controls after HFD feeding for 8 weeks (Figure 5C), suggesting Svep1 induces VSMC proliferation.

To further explore the effects of Svep1 on VSMCs, we generated and purified recombinant Svep1 and its orthologous CAD risk variant (Svep1 ${ }^{\text {CADrv }}$ ) using a mammalian expression system. We tested the response of primary VSMCs to Svep1 that was immobilized on culture plates, reflecting an overexpression-like assay while maintaining its physiologic context as an extracellular matrix protein (in contrast to genetic overexpression). VSMCs adhere to Svep1 in a dose dependent manner (Figure 5D). Exposure to both Svep1 variants induces dose-dependent VSMC proliferation, based on BrdU incorporation (Figure 5E). As a point of reference, we used oxLDL, a proliferative stimulus relevant to atherosclerosis, in addition to Svep1 to test VSMC proliferation. Strikingly, Svep1 was able to induce more VSMC proliferation than oxLDL. Exposure to a combination of oxLDL and Svep1, as exists within the atheromatous environment, caused the greatest amount of VSMC proliferation (Figure 5F). 
241 Murine macrophages exposed to Svep1 do not proliferate in the absence or presence of oxLDL (Figure

242 S5C) suggesting that Svep1 is not a proliferative stimulus for all cell types.

Integrin $\alpha 9 \beta 1$ is expressed by VSMCs, binds to Svep1, and drives proliferation in some cell types (Schreiber et al., 2009). Therefore, to begin to interrogate the molecular mechanisms by which Svep1 influences VSMCs, we tested whether Svep1 exposure was able to induce integrin signaling in VSMCs. We tested this by seeding cells to wells coated with bovine serum albumin (as an inert protein control), VCAM-1 (a low affinity integrin $\alpha 9 \beta 1$ ligand), or Svep1 (a high affinity integrin $\alpha 9 \beta 1$ ligand).

We found that cells adherent to Svep1 had increased phosphorylation of canonical integrin signaling kinases, such as focal adhesion kinase (FAK), Paxillin (Pax), and Src, as well as downstream MAPK kinases, ERK and p38 (Figure 5G), relative to an inert protein control. Svep1 ${ }^{\text {CADrv }}$ had similar effects as Svep1 on integrin signaling in VSMCs (Figure S5D). We then tested if Svep1-induced proliferation was dependent on integrin $\alpha 9 \beta 1$. Since Itg $\alpha 9$ exclusively heterodimerizes with Itg $\beta 1$, we used siRNA knockdown of Itg $\alpha 9$ to disrupt integrin $\alpha 9 \beta 1$. The proliferative effect of Svep1 was completely inhibited by knockdown of $\operatorname{Itg} \alpha 9$ using two different siRNA constructs (Figure $5 \mathrm{H}$ ), suggesting that integrin $\alpha 9 \beta 1$ is necessary for Svep1-induced VSMC proliferation.

\section{Svep1 regulates key VSMC differentiation pathways}

We next sought to characterize the response of primary VSMCs to the wildtype Svep1 and Svep $1^{\text {CADrv }}$ proteins using an unbiased methodology. Cells were collected after 20 hours of growth on the indicated substrate and transcriptomic analysis was performed using RNA-sequencing. Pathway and gene ontology analysis was used to determine the shared and unique transcriptional response to the Svep1 variants. Consistent with previous findings, a number of cell adhesion and proliferation-related pathways and terms were enriched in the shared transcripts of cells exposed to either Svep1 variant.

These include ECM-receptor interaction, focal adhesion, integrin-mediated signaling, positive regulation of cell proliferation, and various additional proliferative and mitogenic pathways (Figure 6A, B, Supplemental Table 1). A striking number of differentiation and development-related pathways and terms were also enriched in cells exposed to the Svep1 variants. These include angiogenesis, cell differentiation, and wound healing, among many others (Figure 6A, B, Supplemental Table 1). developmental roles and may therefore be governing the effects of Svep1 on VSMCs. Further, although Svep $1^{-/}$and $\operatorname{Itg} \alpha 9^{-/-}$mice have similar phenotypes of edema and lymphatic defects (Karpanen et al., 2017; Morooka et al., 2017), the phenotype of Svep $1^{-/-}$mice is markedly more severe (death by E18.5 vs 
P12 (Huang et al., 2000)), suggesting Itg $\alpha 9$ may have partial redundancy with an additional receptor(s)

for Svep1. To search for evidence of additional domain interactions, we cross-referenced the transcriptional profile of VSMCs to the Svep1 variants with InterPro (Mitchell et al., 2019), a database of protein domains. In addition to integrin-related domains, transcripts that code for EGF-like domaincontaining proteins were highly differentially expressed in cells exposed to Svep1 (Figure 6C). Repeat EGF-like domains often interact, as occurs in Notch signaling, suggesting Svepl's repeat EGF-like domains may be playing an important, but as of yet undescribed role in the biological function of Svep1 (Mitchell et al., 2019). Indeed, transcripts related to Notch signaling were dysregulated in cells exposed to Svep1 (Figure 6A).

As an orthogonal approach to interrogating SVEP1's mechanisms and potential binding partners, we sought to identify homologues in distantly related species. The Drosophila protein, uninflatable, is a potential orthologue of SVEP1 (Sonnhammer and Ostlund, 2015) and contains a region defined by three ephrin-receptor like domains, followed by tandem EGF-repeats and a Laminin-G domain (MarchlerBauer et al., 2011), mirroring a region of SVEP1 that contains a highly similar sequence of domains. Inhibition of uninflatable in Drosophila larvae results in defective tracheal development, analogous to the vascular defects observed in zebrafish Svep1 mutants (Ghabrial and Krasnow, 2006; Zhang and Ward, 2009). Uninflatable has been shown to bind and modulate Notch signaling in Drosophila (Loubery et al., 2014; Xie et al., 2012; Zhang and Ward, 2009). These findings, in addition to the RNAseq analysis, led us to hypothesize that Svep1 may also modulate Notch signaling.

VSMCs express multiple Notch receptors (Davis-Knowlton et al., 2019), thus, we tested the impact of Svep1 on Notch signaling in VSMCs. This was assessed by seeding VSMCs on tissue culture plates treated with Svep1 or BSA (as an inert control protein) for 4 hours, since Notch signaling is highly temporally regulated (Schweisguth, 2004). Cells grown on Svep1 had significantly increased expression of canonical Notch targets Hey2 and Hesl even without overexpression of a Notch receptor (Figure 6D). Conversely, primary VSCMs collected from Svep $1^{S M C \Delta / \Delta}$ mice have decreased transcription of Notch target genes (Figure 6E), supporting the regulation of Notch signaling by Svep1. Svep1induced proliferation was also completely abrogated upon Notch inhibition by the $\gamma$-secretase inhibitor, DAPT (Figure 6F). Cell proliferation in response to $10 \%$ fetal bovine serum was not significantly inhibited by DAPT (data not shown), demonstrating that Notch signaling is necessary for Svep1-induced proliferation. It is possible that Notch and integrin receptors may cooperatively regulate the effects of SVEP1, similar to that reported on non-canonical ECM Notch regulators MAGP2 and EGFL7 (Deford et al., 2016). 


\section{VSMCs differentially respond to Svep1 ${ }^{\text {CADrv }}$ compared to Svep1}

Our experimental atherosclerosis models and Mendelian Randomization analysis indicate that both SVEP1 variants are atherogenic, with Svep1 ${ }^{\text {CADrv }}$ having the greater atherogenicity of the two. We therefore interrogated the differential transcriptional responses of VSMCs to the Svep1 variants. This analysis also revealed that a large number of proliferation-related pathways were disproportionately regulated by the variants (Figure 6G, H, Supplementary Table 1). Further exploration revealed that the

311 fibroblast growth factor (FGF) receptor family was differentially expressed between the variants. The

312 FGFR family is also sub-categorized within several of the most differentially regulated pathways and

313 terms. FGF signaling is proatherogenic in VSMCs (Chen et al., 2016), so we assessed the effect of each

314 variant on the direction and magnitude of transcription of each FGF receptor expressed by VSMCs.

315 Consistent with their relative atherogenicities, SVEP1 increases expression of FGF receptors but 316 exposure to Svep1 ${ }^{\text {CADrv }}$ resulted in significantly higher expression of FGF receptors (Figure 6I). These

317 data suggest that increased FGF signaling may contribute to the increased CAD risk associated with 318 SVEP1 ${ }^{\text {CADrv }}$.

319 Given the fundamental role of integrin, Notch, and FGFR signaling in regulating VSMC phenotype, we assessed the effects of Svep1 in response to oxLDL, an inflammatory stimulus relevant to atherosclerosis. Upon oxLDL stimulation, both Svep $1^{S M C+/+}$ and Svep $1^{S M C \Delta / \Delta}$ VSMCs decreased the expression of contractile markers Myh11 and SM $\alpha$-actin (Figure 6J), while increasing expression of the inflammatory markers $\mathrm{Il}-6$ and $\mathrm{Ccl} 2$ (Figure 6K), confirming an inflammatory response to oxLDL.

Cxcl1, Il-6, and Ccl2 expression was lower in Svep $1^{S M C \Delta / \Delta}$ VSMCs than Svep $1^{S M C+/+}$ controls, suggesting

\section{Svep1 promotes inflammation in atherosclerosis}

To investigate how the loss of Svepl influences pathways involved in the development of atherosclerosis at the tissue level, we performed RNA-seq analyses on mRNA extracted from aortic arches of Svep $1^{S M C+/+}$ and Svep1 $1^{S M C \Delta / \Delta}$ mice after 8 weeks of HFD. Loss of Svep1 in VSMCs altered a number of inflammatory pathways upon induction of atherosclerosis. These include cytokine-cytokine receptor interaction, chemokine signaling, and NF-kappa B signaling pathways (Figure 7A, B). Notably, both cell adhesion molecules (CAMs) and ECM-receptor interaction were also dysregulated in the atherosclerotic aortic arches from Svep $1^{S M C \Delta / \Delta}$ (Figure 7A, B and Supplementary Table 2). Quantitative PCR using cDNA from the aortic arches of the same mice was used to validate the RNA-seq results. 
osteopontin), and Cxcl5 (C-X-C motif chemokine ligand 5) were significantly decreased in Svep $1^{S M C \Delta / \Delta}$ mice, as compared to Svep $1^{S M C+/+}$ mice (Figure S6A). Despite these differences, we did not find a significant alteration in circulating inflammatory mediators in these mice, suggesting Svep1 influences local tissue inflammation but not systemic inflammation (Figure S6B). These data are also consistent with our observations that Svep1 depletion decreases neointimal macrophage staining in atherosclerotic 342 plaque.

Integrins play a critical role in the immune response, we therefore asked whether immune cells may also express integrin $\alpha 9 \beta 1$ and interact with SVEP1 in atherosclerosis. In human peripheral blood cells, moderate integrin $\alpha 9 \beta 1$ expression was detected by neutrophils and low expression was detected by $\mathrm{CD} 14^{\text {low }} \mathrm{CD} 16^{+}$non-classical, $\mathrm{CD} 14^{\text {high }} \mathrm{CD} 16^{+}$intermediate, and $\mathrm{CD} 14^{+} \mathrm{CD} 16^{-}$classical monocytes (Figure S7A) as previously reported (Shang et al., 1999). Given that monocytes significantly alter their expression profiles upon tissue entry and differentiation into macrophages (Chistiakov et al., 2015), we sought to test if macrophages in atherosclerotic plaque express ITGA9. Indeed, ITGA9 expression was detected in $\mathrm{CD}_{68}^{+}$macrophages within human atherosclerotic plaque by in situ hybridization (Figure S7B).

We then sought to further assess the expression of integrin $\alpha 9 \beta 1$ expression in circulating murine leukocyte subsets. High expression of integrin $\alpha 9 \beta 1$ was detected in both Ly $6 \mathrm{C}^{\text {hi }}$ and Ly6C ${ }^{\text {low }}$ monocytes and we could detect low levels in neutrophils (Figure 7C). These expression patterns were unaltered in heterozygous Svep1 deficiency (Figure S7C) and we did not observe an induction of integrin $\alpha 9 \beta 1$ expression upon oxLDL treatment in any cell type tested (Figure S7D, E). Considering the finding that integrin $\alpha 9 \beta 1$ is expressed by monocyte subsets in peripheral mouse blood, we further analyzed its expression in myeloid cells from the aortas of $\mathrm{Apoe}^{-/-}$and Svep $1^{+/} \mathrm{Apoe}^{-/-}$mice following 8 weeks of HFD feeding. We discovered that integrin $\alpha 9 \beta 1$ was expressed in both macrophages and Ly6C ${ }^{\text {hi }}$ monocytes of these mice (Figure 7D), consistent with human expression data. We similarly detected robust expression of $\operatorname{Itg} \alpha 9$ by neointimal macrophages using in situ hybridization (Figure 7E).

Since integrin $\alpha 9 \beta 1$ is expressed on monocytes/macrophages, we sought to better understand whether Svep1 could be directly interacting with integrin $\alpha 9 \beta 1$ on these cells. To test this, we generated mice with myeloid cell lineage-specific knockout of Itga9 using LysM-Cre (Itg $\alpha 9^{\text {floxflox }}$ LysM-Cre,

controls. First, we confirmed that bone marrow derived macrophages from $\operatorname{Itga} 9^{M A C \Delta / \Delta}$ animals had a significant reduction in the amount of integrin $\alpha 9 \beta 1$ that was present on the cell surface (Figure 7F). We then tested the ability of peritoneal macrophages from these animals to migrate in response to Svep1 
using a trans-well migration assay. Svep1 exposure induced a dose-dependent trans-well migration of macrophages from $\operatorname{Itga} 9^{M A C+/+}$ control animals but not from $\operatorname{Itga} 9^{M A C \Delta / \Delta}$ mice (Figure $\left.7 \mathrm{G}\right)$. This suggests that Svep1 and integrin $\alpha 9 \beta 1$ may directly interact to augment myeloid cell homing or migration. Consistent with this, THP-1 cells, a human monocytic cell line, adhered to Svep1 in a dose-dependent manner (Figure S7F, G). Integrin signaling was also activated in THP-1 cells upon exposure to Svep1 or Svep $1^{\text {CADrv }}$ and no differences were observed between the variants (Figure S7G).

To test if Svep1 had similar effects on leukocytes in vivo, we performed an in vivo monocyte recruitment assay in Svep $1^{S M C+/+}$ and Svep $1^{S M C \Delta / \Delta}$ mice. After 8 weeks of HFD feeding, we injected yellow/green (YG) latex beads intravenously in order to label circulating Ly6C $\mathrm{C}^{\text {low }}$ monocytes. Flow cytometry was performed three days after intravenous bead injection (to confirm labeling) and the aortic tissues were isolated for histology on the fourth day following bead injection (to assess recruitment). We confirmed that YG beads were preferentially labeled on Ly6 $\mathrm{C}^{\text {low }}$ monocytes and not on Ly6Chigh monocytes, indicating efficient bead labeling of circulating monocytes (Figure S7H). We did not observe a difference between groups in the efficiency of bead labeling for monocyte subsets (Figure S7I). Next, we quantified the number of labeled monocytes recruited into atherosclerotic plaques of aortic roots using fluorescent microscopy. Svep $1^{S M C \Delta / \Delta}$ mice had significantly fewer YG beads per atheroma, with or without normalization to the percentage of labeled monocytes, relative to Svep $1^{\text {SMC+/+ }}$ mice (Figure 7H).

Taken together, these data support Svep1's role in promoting inflammation in atherosclerosis, either indirectly by promoting an inflammatory VSMC phenotype, directly by interacting with integrin $\alpha 9 \beta 1$ on circulating or tissue leukocytes, or a combination of these processes.

\section{Discussion} and Stitziel, 2019), but a significant limitation in translating their findings is the identification of specific causal genes that underlie the observed statistical associations. In a previous study, we identified a lowfrequency polymorphism in SVEPI that robustly associated with coronary artery disease risk in humans (Stitziel et al., 2016), but it was not clear if SVEP1 was the causal gene in the locus. Here, we present the

first report that SVEP1 is causal in coronary artery disease using experimental mouse models and Mendelian Randomization.

Atherosclerosis is a complex, multifactorial disease process with numerous cell types playing a role in its pathogenesis. This presents an arduous challenge when validating genomic risk loci and 
401 testing their mechanisms. The SVEP1 ${ }^{\text {CADrv }}$ does not associate with changes in plasma lipid levels

402 (Stitziel et al., 2016), prompting us to explore how SVEP1 might influence other aspects of disease 403 pathogenesis. We used human and mouse expression data at the cell and tissue level to develop 404 mechanistic hypotheses, which we then tested using in vivo and in vitro approaches. Specifically, high 405 basal arterial expression of both SVEP1 and ITGA9, and increased SVEP1 expression under pathological 406 conditions, led us to hypothesize that these proteins may influence local disease processes. Upon 407 exposure to various pathologic stimuli, VSMCs can undergo a "phenotype shift", in which they lose 408 their quiescent, contractile properties and become migratory, proliferative, inflammatory, and synthetic 409 (Basatemur et al., 2019; Bennett et al., 2016). VSMCs gain properties of matrix-synthesizing fibroblasts 410 during atherosclerosis (Wirka et al., 2019), making VSMCs our primary candidates for the source of 411 SVEP1 within atherosclerotic plaque. Our results provide strong evidence that atherogenic SVEP1 is 412 indeed synthesized by VSMC-derived cells within the atherosclerotic plaque.

413 We then used expression of ITGA9 to identify disease-relevant cell types that may respond to

414 SVEP1. This led to the hypothesis that SVEP1 may be interacting with VSMCs by an autocrine 415 mechanism or monocytes by a paracrine mechanism to promote atherosclerosis. VSMCs play a 416 particularly complex and intriguing role in atherosclerosis and warrant further discussion. Recent 417 lineage tracing studies have challenged the notion that VSMCs play a protective role in atherosclerosis 418 (Bennett et al., 2016) by demonstrating that a large, heterogenous population of cells within plaque are 419 derived from VSMCs (Basatemur et al., 2019; Bennett et al., 2016; Shankman et al., 2015).

420 Furthermore, numerous CAD risk loci have now been linked to VSMCs (Liu et al., 2018). This study 421 demonstrates that Svep1 profoundly influences the behavior of VSMCs by regulating a number of 422 pathways with vital roles in VSMC biology. These pathways include integrin, Notch, and FGFR 423 signaling, each of which has been shown to contribute to atherosclerosis (Boucher et al., 2012; Chen et 424 al., 2016; Fukuda et al., 2012; Misra et al., 2018). Recent studies have provided novel insights into the 425 regulation of VSMC phenotype in atherosclerosis by various transcription factors (Cherepanova et al., 426 2016; Shankman et al., 2015; Wirka et al., 2019). The ECM also plays a fundamental role in regulating 427 VSMC phenotype and is amenable to pharmacologic intervention. Current strategies for the treatment 428 and prevention of CAD consist of lowering risk factors, such as plasma lipids, yet substantial residual 429 risk remains despite effective treatment. Intervening on VSMCs may be a powerful complimentary 430 approach to these traditional therapies.

431 In addition to its association with CAD, our Mendelian randomization results suggest that 432 circulating SVEP1 causally underlies risk of hypertension and type 2 diabetes. Although the source of 
433 SVEP1 in human plasma is unknown, other ECM proteins have been detected in the circulation of

434 patients with atherosclerosis, suggesting that plasma levels of these proteins may reflect tissue levels and 435 atherosclerotic remodeling (Langley et al., 2017; Sundstrom and Vasan, 2006). The mechanisms by 436 which the genetic variants used in the Mendelian randomization affect plasma SVEP1 levels is unclear. 437 Two reasonable hypotheses include modification of protein secretion or degradation, however further 438 studies will be required to determine these mechanisms. Regardless, the power of the two sample 439 Mendelian randomization framework is that these alleles are allocated randomly at birth and are 440 associated with SVEP1 levels in the absence of disease, suggesting that the presence of disease is not 441 driving altered SVEP1 levels, but rather that altered SVEP1 levels are causally related to disease. This 442 further suggests that circulating SVEP1 levels have the potential to be useful as a predictive biomarker. 443 Additional human genetic data also supports a broader role of SVEP1 in cardiometabolic disease. 444 The alpha subunit of integrin $\alpha 9 \beta 1$, which binds to SVEP1 (Sato-Nishiuchi et al., 2012) with an affinity 445 that far exceeds its other known ligands (Andrews et al., 2009; Hakkinen et al., 2000; Nishimichi et al., 446 2009; Smith et al., 1996), is also associated with blood pressure in multiple studies (Levy et al., 2009; 447 Takeuchi et al., 2010). Overexpression of disintegrin and metalloproteinase with thrombospondin 448 motifs-7 (ADAMTS-7), another CAD risk locus, in primary rat VSMCs alters the molecular mass of 449 SVEP1 (Kessler T, 2015). The overlapping disease associations and molecular interactions between 450 these three risk loci converge on SVEP1 and point to a regulatory circuit with a prominent, yet 451 unexplored role in cardiometabolic disease. Further studies will be required to validate their interactions 452 and mechanisms in vivo, and to explore the potential of targeting this pathway for the treatment of 453 cardiometabolic disease.

454 Our complementary mouse models demonstrate that Svep1 haploinsufficiency and VSMC455 specific Svep1 deficiency significantly abrogate the development of atherosclerosis. Each intervention 456 was well tolerated by mice, as we did not observe any adverse response to Svep1 depletion. Similarly, 457 our Mendelian Randomization analyses suggest there may be a therapeutic window to safely target 458 SVEP1 levels. These findings suggest that targeting SVEP1 or selectively modulating its interactions 459 may be a viable strategy for the treatment and prevention of coronary artery disease. 
Figure 1. SVEP1 is expressed by VSMCs under pathological conditions.

463 (A) Expression of SVEP1 in human aortic wall and LIMA cross-sections from patients using ISH.

464 (B) $\beta$-gal expression in the aortic root, BCA (brachiocephalic artery), LC (lesser curvature) from 8-

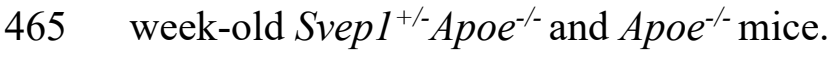

466 (C) Expression of Svepl using ISH in aortic root from young (8-week-old), CD fed and 8 weeks of HFD 467 fed Apoe $^{-/-}$and Svep 1 ${ }^{+/-}$Apoe - $^{-/}$mice.

468 (D) Expression of Svep1 using ISH in the aortic root from Svep $1^{S M C+/+}$ and Svep $1^{S M C \Delta / \Delta}$ mice after 8 469 weeks of HFD feeding. Outlined areas indicate the regions magnified in the next panels. Tissues in (A470 D) were co-stained with the VSMC marker, SM $\alpha$-actin. Scale bars, $50 \mu \mathrm{m}$. M, media; L, lumen; P, 471 plaque.

(E) Svep1 expression of primary VSMCs from Svep $1^{S M C+/+}$ and Svep $1^{S M C \Delta / \Delta}$ mice with or without the 473 addition of oxLDL for $48 \mathrm{hr}$. Increased expression of CD36, the oxLDL receptor, confirms VSMC 474 stimulation. $* * * P<0.001 ; * * * * P<0.0001$. Mann-Whitney test was used.

Figure 2. Svep1 haploinsufficiency abrogates atherosclerosis.

477 (A) Body weight of Apoe $e^{-/}$and Svep $1^{+-}$Apoe $^{-/}$mice during HFD feeding ( $n=13$-14/group).

478 (B) Plasma total cholesterol ( $n=7-10)$, triglycerides, and glucose ( $n=12-13$ /group).

479 (C) En face Oil Red O-stained aortas. Outlined areas indicate the aortic arch regions magnified in left 480 panels. Quantification of Oil Red O-stained area in each aortic arch and whole artery ( $n=15-17 /$ group).

481 (D) Oil Red O-stained aortic root cross-sections. Quantification of Oil Red O-stained area $(n=15-$

482 17/group). Scale bar, $500 \mu \mathrm{m}$.

483 (E) Mac3 staining in aortic root sections. Quantification of Mac3 as a percentage of plaque area $(n=11$ 484 12/group). Scale bar, $200 \mu \mathrm{m}$. M, media; L, lumen; P, plaque. One-way ANOVA test (A) or Unpaired 485 nonparametric Mann-Whitney test were used (B through E), and shown as the mean $\pm \mathrm{SEM}$. ${ }^{*} P<0.05$; $486 * * P<0.01 ; N S$, not significant.

489 (A) Body weight of Svep $1^{S M C+/+}$ and Svep $1^{S M C \Delta / \Delta}$ mice during HFD feeding.

490 (B) Total plasma cholesterol, triglycerides, and glucose. 
491 (C) En face Oil Red O-stained aortas. Outlined areas indicate the aortic arch regions magnified in left

492 panels. Quantification of Oil Red O-stained area in each aortic arch and whole artery.

493 (D) Oil Red O-stained aortic root cross-sections. Quantification of Oil Red O-stained area. Scale bar,

$494500 \mu \mathrm{m} . n=13-15 /$ group (A through D).

495 (E) Mac3 staining of aortic roots. Quantification of Mac3 as a percentage of plaque area.

496 (F) Necrotic core outlined on H\&E-stained sections.

497 (G) Collagen staining using by Masson's trichrome stain. (E through G) All values were calculated as a

498 percentage of plaque area. Scale bars, $200 \mu \mathrm{m} . n=8-9$ /group. M, media; L, lumen; P, plaque. One-way 499 ANOVA test (A) or Unpaired nonparametric Mann-Whitney test were used (B through G), and shown 500 as the mean \pm SEM. $* P<0.05 ; * * P<0.01 ; * * * P<0.001 ; N S$, not significant.

Figure 4. Plasma levels of SVEP1 are causally related to CAD in humans.

504 the change per alternative allele (ending 2702G) in units of normalized protein levels after adjusting for 505 covariates as previously described (Sun et al., 2018).

506 (B) Genome-wide Manhattan plot for variants associated with plasma SVEP1. The $-\log _{10}(\mathrm{p})$ of the association with SVEP1 levels is plotted for each variant across the genome according to chromosomal position (X-axis). The red line indicates genome-wide significance $\left(P<5 \times 10^{-8}\right)$. The association peak on chromosome 9 overlies the SVEP1 locus.

(C) Estimated effect (with 95\% confidence intervals) of each variant included in the Mendelian

Randomization analysis on plasma SVEP1 level and CAD risk. The red line indicates the causal effect estimate $\left(P=7 \times 10^{-11}\right)$.

(D) The estimated causal effect (with 95\% confidence intervals) of each SNP included in the Mendelian

Randomization analysis for a one unit increase in SVEP1 level is plotted along with the overall

Figure 5. Svep1 induces Itga9-dependent proliferation in VSMCs.

518 (A) ITGA9 expression in human aortic wall and LIMA cross-sections from patients using ISH. M, 519 media; L, lumen.

520 (B) Expression of $\operatorname{Itg} \alpha 9$ in the aortic root from 8-week-old Svep $1^{S M C+/+}$ and Svep $1^{S M C \Delta / \Delta}$ mice using ISH. 521 Outlined areas indicate the regions magnified in the next panels. Scale bar, $50 \mu \mathrm{m}$. 
(C) MCM-2 immunofluorescent staining of aortic root regions from Svep $1^{S M C+/+}$ and Svep $1^{S M C \Delta / \Delta}$ mice after 8 weeks of HFD feeding. Yellow arrows indicate $\mathrm{MCM}-2^{+} / \mathrm{SM} \alpha-a c t i n{ }^{+}$cells within plaque. Quantification of $\mathrm{MCM}^{+}{ }^{+} / \mathrm{SM} \alpha-$ actin $^{+}$cells $(\mathrm{n}=13-15 /$ group$)$. Scale bars $=50 \mu \mathrm{m}$. Tissues in $(\mathrm{A}-\mathrm{C})$ were co-stained with the VSMC marker, SM $\alpha$-actin.

526 (D) Adhesion of VSMCs to increasing concentrations of immobilized Svep1. Adhered cells were 527 counted manually and normalized to wells lacking Svep1.

528 (E) Proliferation of VSMCs in response to increasing concentrations of immobilized Svep1 and 529 Svep1 $1^{\text {CADrv }}$ using a BrdU incorporation assay.

530 (F) Svep $1^{S M C \Delta / \Delta}$ VSMCs were incubated in wells precoated with $30 \mu \mathrm{g} \mathrm{ml}^{-1}$ Svep1 protein or BSA (as 531 vehicle control) and treated with or without $50 \mu \mathrm{g} \mathrm{ml}^{-1}$ oxLDL in the culture media for $36 \mathrm{hr}$.

532 Proliferation was determined by BrdU incorporation. Two-tailed t-test.

533 (G) Immunoblots of integrin signaling kinases and downstream kinases of cells adhered to control, 534 VCAM-1, or Svep1-treated plates. $\beta$-actin was used as loading control.

535 (H) VSMCs were transfected with control or Itga9-targetted siRNAs and grown on immobilized Svep1 536 or BSA. Proliferation was determined by BrdU incorporation. $* P<0.05$; *** $P<0.001 ; * * * * P<$ 537 0.0001. Two-tailed t-test.

Figure 6. Svep1 modulates key VSMC-developmental pathways

540 (A-C) Common transcriptional response of VSMCs to Svep1 and Svep1 ${ }^{\text {CADrv }}$ proteins. Dysregulated (A)

541 KEGG pathways, (B) GO term molecular functions, and (C) InterPro domains. Top 5 dysregulated

542 categories plus additional, select categories are included. Full results are available in Supplemental

543 Table 1 . Bars represent $-\log _{10}$ of $P$ values.

544 (D) Transcription of canonical Notch target genes after 4 hours of adhesion to Svep1, relative to BSA.

545 Two-tailed t-test.

546 (E) Basal transcription of Notch target genes in Svep $1^{S M C+/+}$ and Svep $1^{S M C \Delta / \Delta}$ VSMCs. Two-tailed t-test.

547 (F) Proliferation of VSMCs in response to immobilized Svep1. Cells were treated with DMSO (carrier) 548 or $25 \mu \mathrm{M}$ DAPT. Proliferation was determined by BrdU incorporation. Two-tailed t-test.

549 (G-H) Differential transcriptional response of VSMCs to Svep1 and Svep1 ${ }^{\text {CADrv }}$ proteins. Dysregulated 550 (A) KEGG pathways, (B) GO term molecular functions. Top 5 dysregulated categories plus additional, 551 select categories are included. Full results are available in Supplemental Table 1. Bars represent - $\log _{10}$ of $552 P$ values. 
553 (I) Bar graph of Fgfr transcript counts from RNAseq. Each transcript is normalized to the BSA control 554 group. Two-tailed t-test.

$555(\mathrm{~J}, \mathrm{~K})$ qPCR of $(\mathrm{J})$ VSMC markers, and $(\mathrm{K})$ inflammatory markers of VSMC cultured with or without 50 $\mu \mathrm{g} \mathrm{ml}^{-1}$ oxLDL for $24 \mathrm{hr} .{ }^{*} P<0.05 ; * * P<0.01 ; * * * P<0.001$.

\section{Figure 7. Svep1 promotes inflammation in atherosclerosis}

559 (A-B) Differential transcriptional profile of atherosclerotic aortic arches from Svep $1^{\text {SMC+/+ }}$ and

560 Svep $1^{S M C \Delta / \Delta}$ mice. Dysregulated (A) KEGG pathways (B) GO term molecular functions. Top 5

561 dysregulated categories plus additional, select categories are included. Full results are available in

562 Supplemental Table 2. Bars represent $-\log _{10}$ of $P$ values.

563 (C) Histogram for Itg $\alpha 9 \beta 1$ expression in mouse blood neutrophils $\left(\mathrm{CD}_{\left.11 \mathrm{~b}^{+} \mathrm{Ly}_{6 \mathrm{G}}{ }^{+}\right) \text {, Ly6C }}^{\text {low }}\right.$

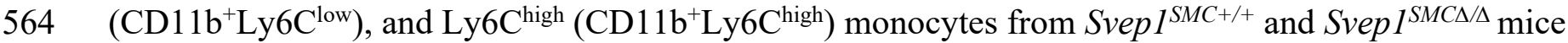

565 after 8 weeks of HFD.

566 (D) Histogram of $\operatorname{Itg} \alpha 9 \beta 1$ expression in the subpopulations of aortic leukocytes. Macrophages

$567\left(\mathrm{CD}^{+} 4^{+} \mathrm{CD} 11 \mathrm{~b}^{+}\right), \mathrm{DCs}\left(\mathrm{CD} 11 \mathrm{c}^{+} \mathrm{MHCII}^{\text {high }}\right)$, neutrophils $\left(\mathrm{CD} 11 \mathrm{~b}^{+} \mathrm{Ly}_{6} \mathrm{G}^{+}\right)$, and $\mathrm{Ly}_{6 \mathrm{C}}$ high

$568\left(\mathrm{CD}_{11 \mathrm{~b}}{ }^{+} \mathrm{Ly} 6 \mathrm{C}^{\text {high }}\right)$ monocytes from $A p o e^{-/-}$and Svep $1^{+/-}$Apoe $^{-/-}$mice after 8 weeks of HFD.

569 (E) Expression of Itga9 in the aortic roots from Svep $1^{S M C+/+}$ and Svep $1^{S M C \Delta / \Delta}$ mice using ISH after 8

570 weeks of HFD. Tissues were co-stained for Mac3 and SM $\alpha$-actin. Scale bars, $50 \mu \mathrm{m}$.

571 (F) Expression of Itg $\alpha 9$ in BMDM from $\operatorname{Itg} \alpha 9^{M A C+/+}$ and $\operatorname{Itg} \alpha 9^{M A C \Delta / \Delta}$ mice.

572 (G) Migratory response of thioglycolate-elicited macrophages from $\operatorname{Itg} \alpha 9^{M A C+/+}$ and $\operatorname{Itg} \alpha 9^{M A C \Delta / \triangle}$ were

573 determined using a chemotaxis chamber incubated with 0, 50, and $200 \mathrm{ng} \mathrm{ml}^{-1}$ of Svep1 protein.

574 Migrated cells were counted by an automated microscope and expressed as cells per field of view.

575 (H) In vivo monocyte recruitment assay. YG-bead uptake within plaque lesion in the aortic root regions 576 from Svep $1^{S M C+/+}$ and Svep $1^{S M C \Delta / \Delta}$ mice. Quantification of YG-bead uptake showing the total number of

577 YG-beads per section (left Y axis), and the number of YG-beads normalized to the percentage of labeled Ly6C ${ }^{\text {low }}$ monocytes (right $\mathrm{Y}$ axis). $n=6-7$ /group. Scale bar, $50 \mu \mathrm{m} .{ }^{*} P<0.05 ; * * P<0.01$. 
Figure 1. SVEP1 is expressed by VSMCs under pathological conditions.

A

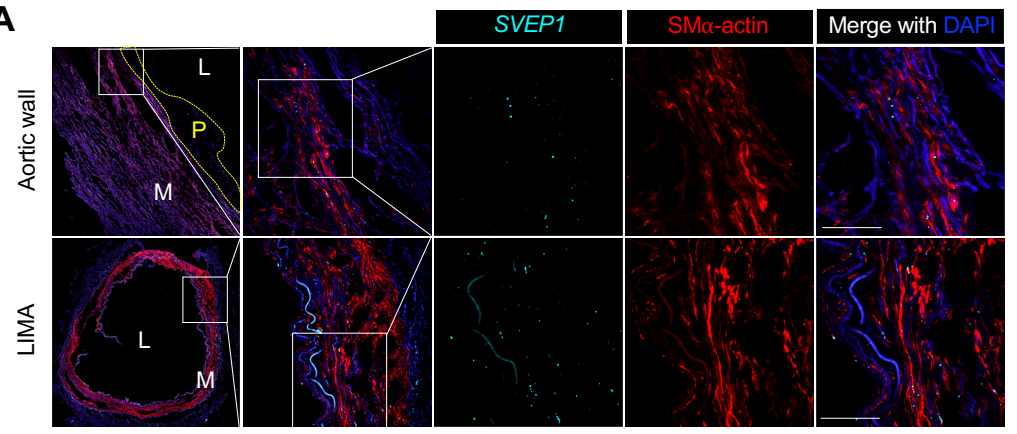

B

B $\quad B C A$

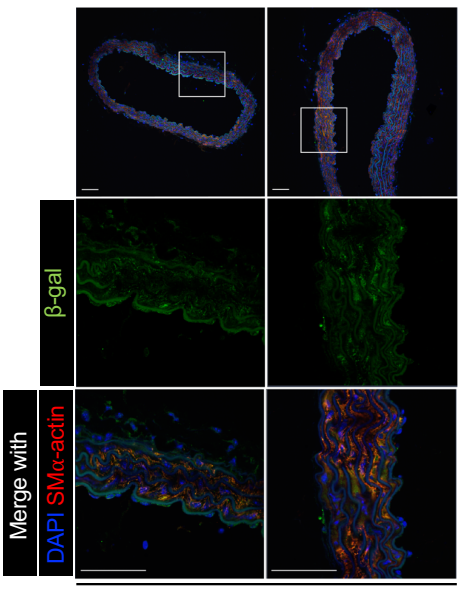

Svep $1^{+/}$Apoe $^{-/}$

D
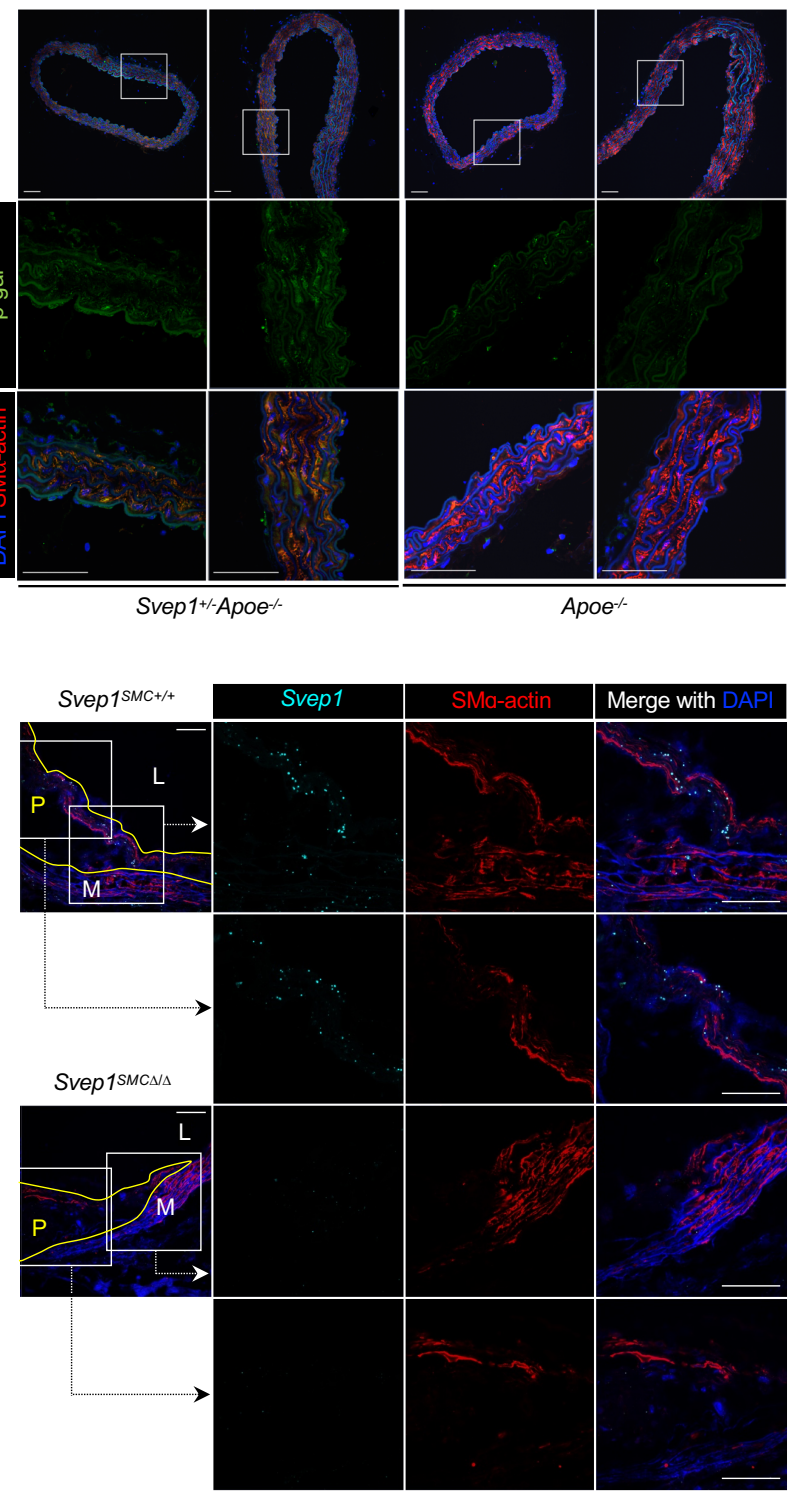

Apoe- -
C

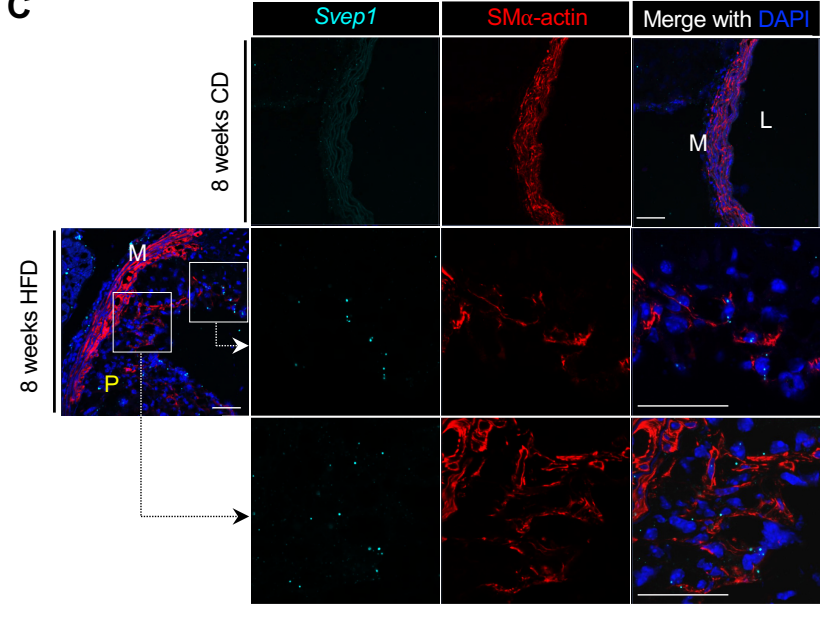

E

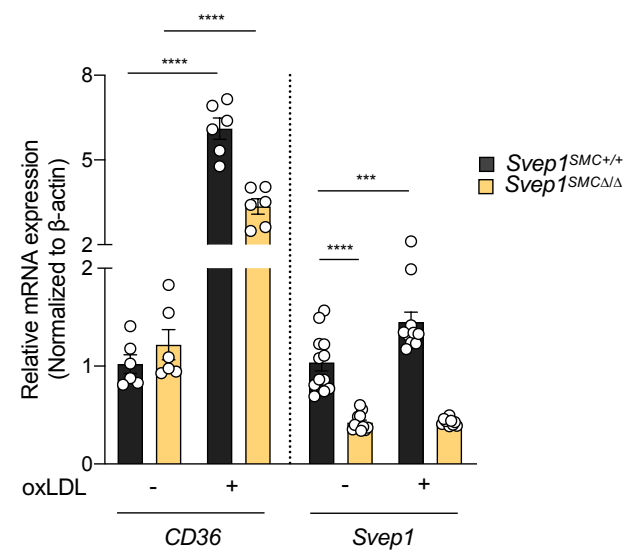




\section{Figure 2. Svep1 haploinsufficiency abrogates atherosclerosis}

A

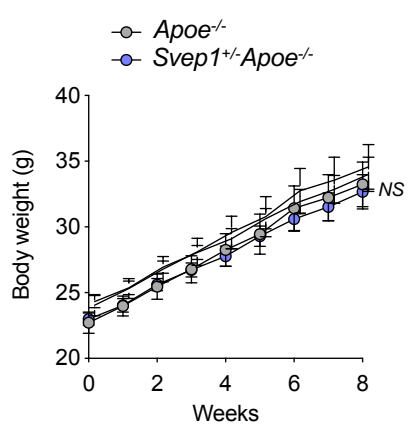

C

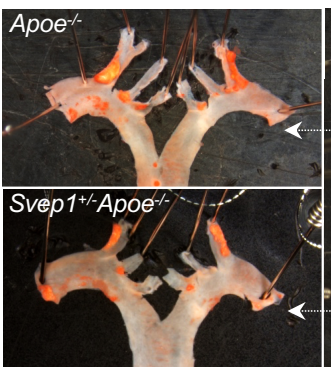

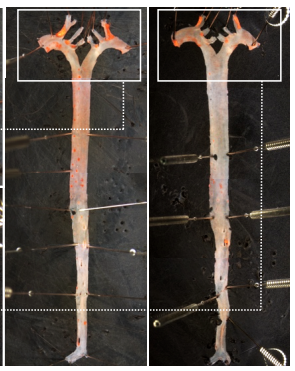

B

$\square$ Apoe ${ }^{-} \quad \square$ Svep $1+-A p o e^{-}$
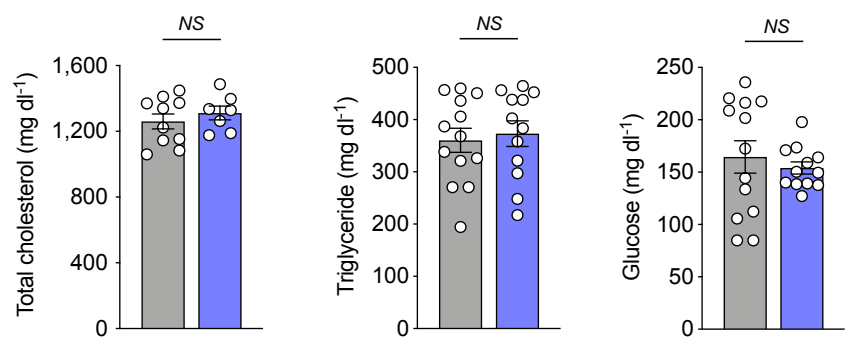

D
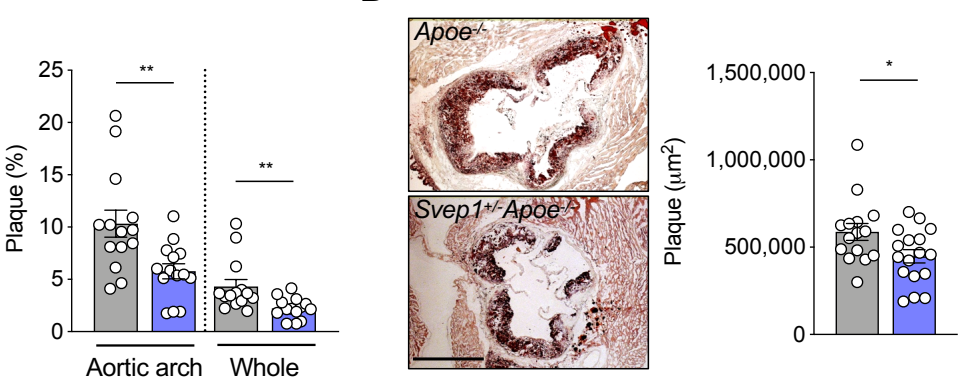

E

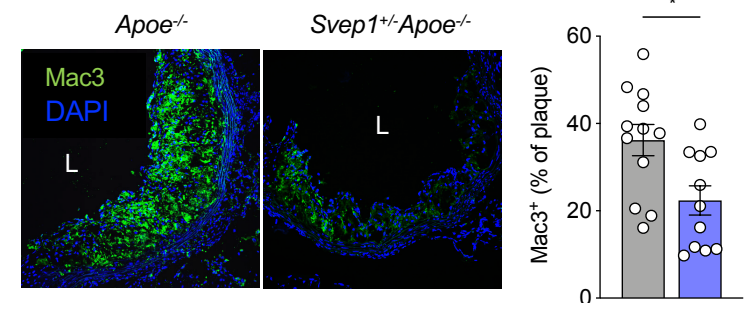


584 Figure 3. VSMC-specific Svep1 deficiency reduces atherogenesis and plaque complexity.

A

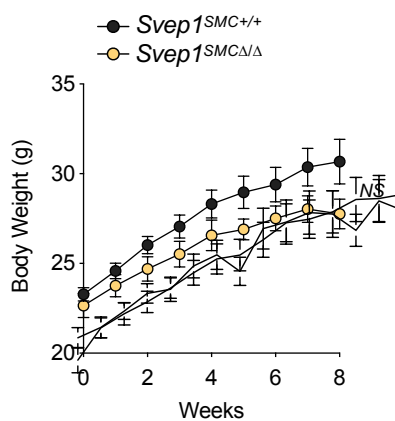

C

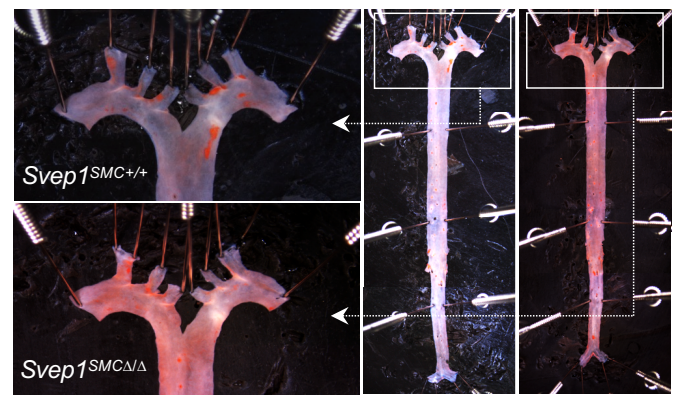

E

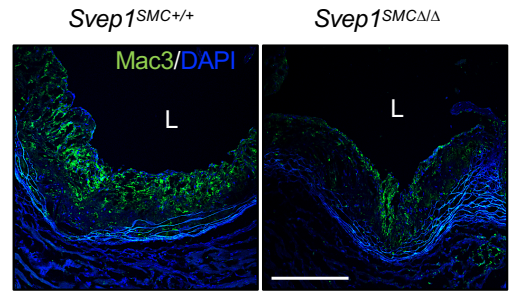

G

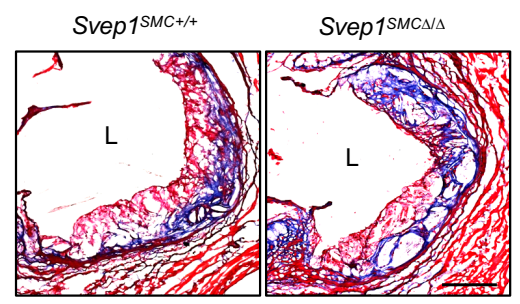

B

- Svep1SMC+/+ $\square$ Svep1SMCA/A
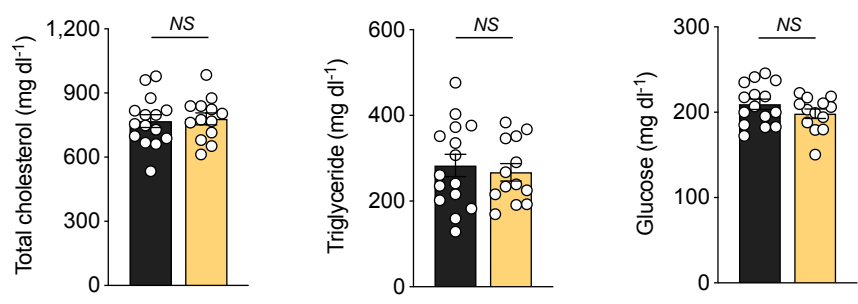

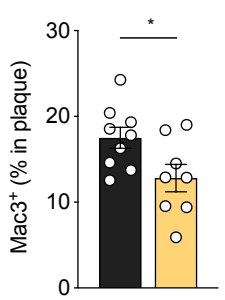

F
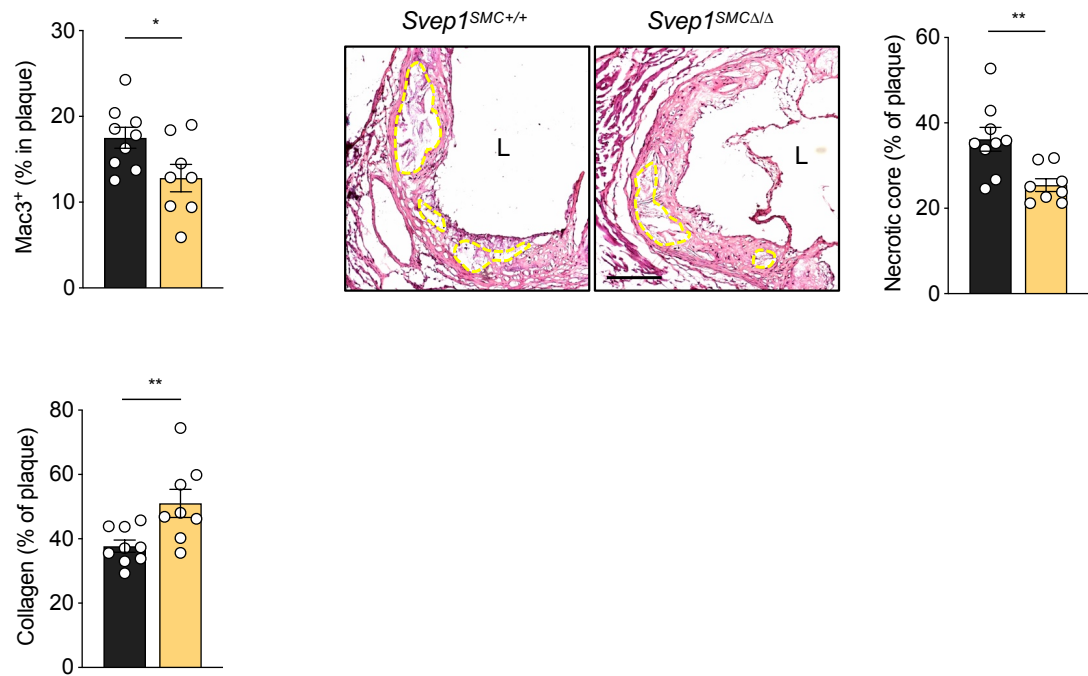
Figure 4. Plasma levels of SVEP1 are causally related to CAD in humans.

A

\begin{tabular}{|c|c|c|c|c|c|}
\hline rsID & $\begin{array}{c}\text { Reference } \\
\text { allele }\end{array}$ & $\begin{array}{c}\text { Alternate } \\
\text { allele }\end{array}$ & $\begin{array}{c}\text { Protein } \\
\text { impact }\end{array}$ & Effect & $P$ value \\
\hline rs11124523 & $\mathrm{C}$ & $\mathrm{T}$ & $\begin{array}{c}\text { SVEP1 } \\
\text { D2702G }\end{array}$ & 0.48 & $8 \times 10^{-14}$ \\
\hline
\end{tabular}

B

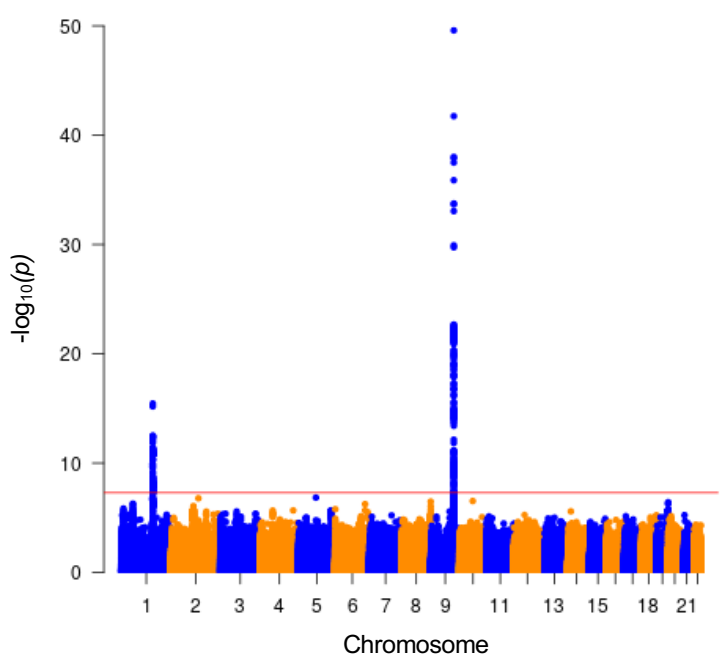

D

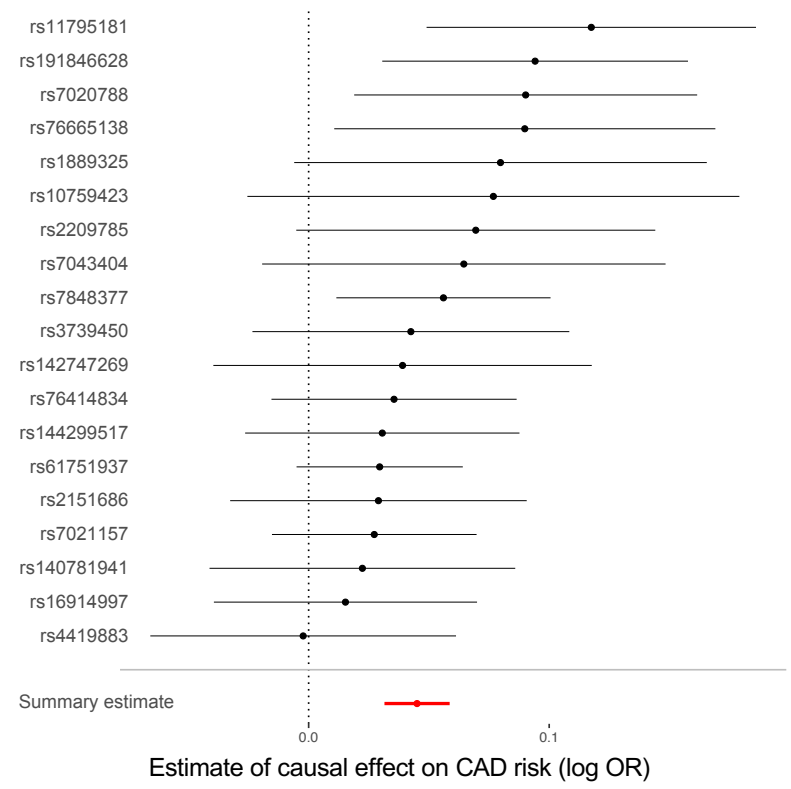

C

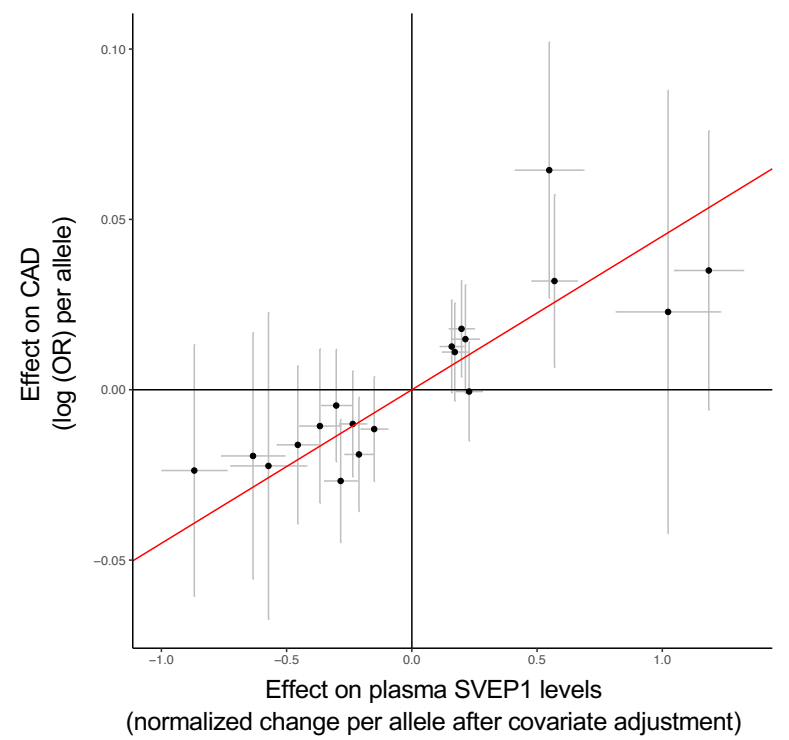


588 Figure 5. Svep1 induces Itga9-dependent proliferation in VSMCs.

A

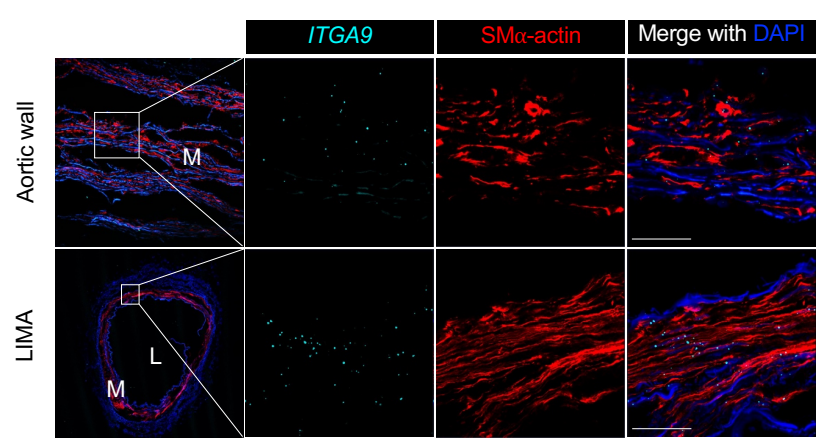

C

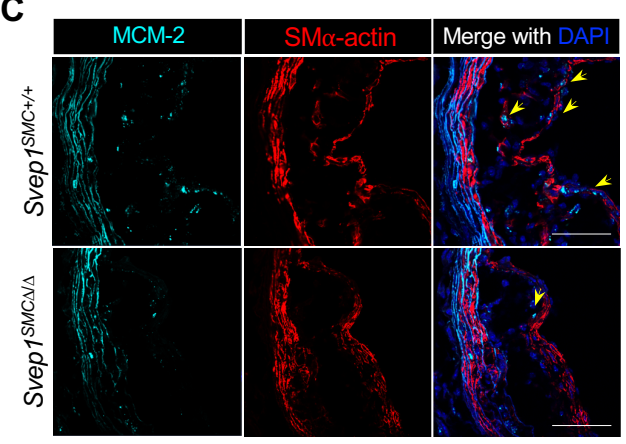

E

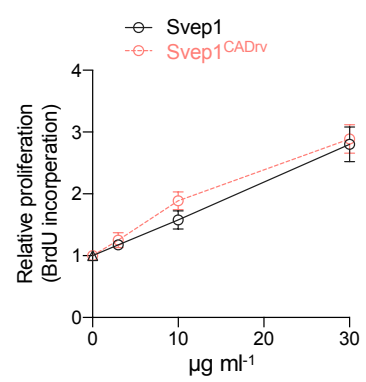

F

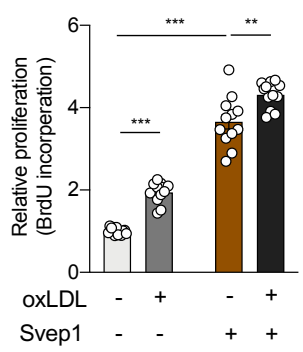

B

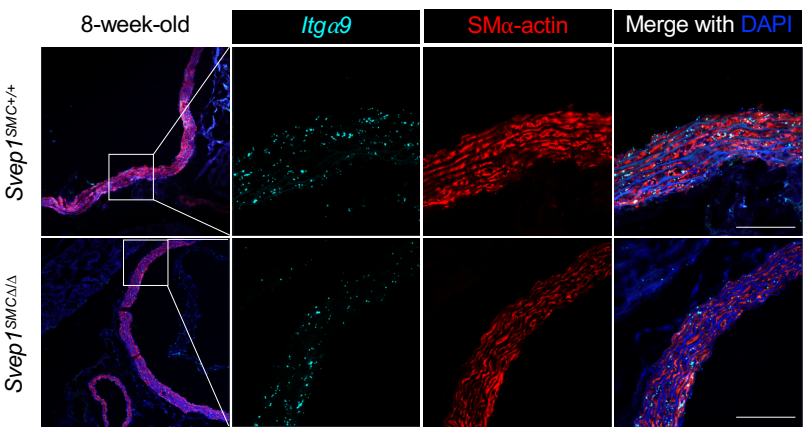

D

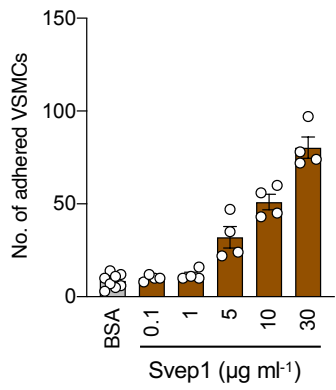

H
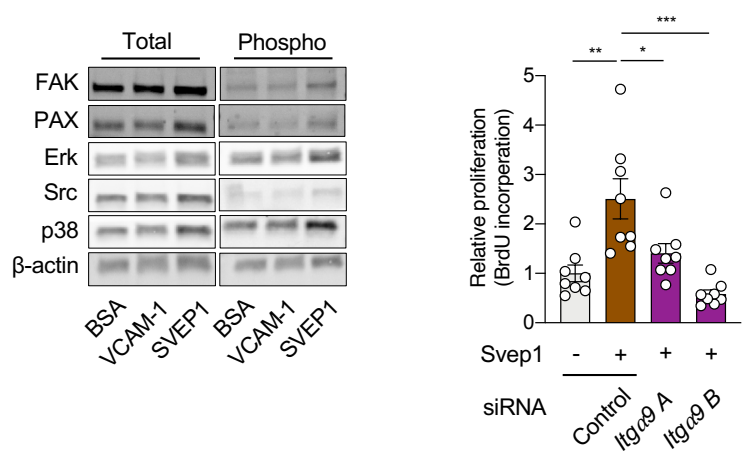
Figure 6. Svep1 modulates key VSMC-developmental pathways

A

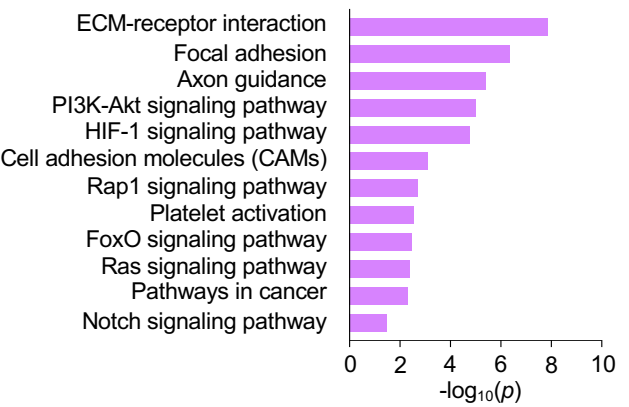

C

Epidermal growth factor-like domain
Insulin-like growth factor binding protein, N-terminal
EGF-like calcium-binding
EGF-like, conserved site

EGF-like calcium-binding, conserved site Integrin alpha chain Integrin alpha-2 Integrin alpha beta-propelle Insulin-like growth factor binding protein, N-terminal, Cys-rich conserved site Integrin alpha chain, C-terminal cytoplasmic region, conserved site Tyrosine-protein kinase, catalytic domain Serine-threonine/tyrosine-protein kinase catalytic domain

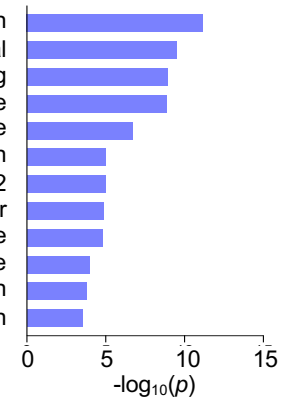

$\mathbf{E}$

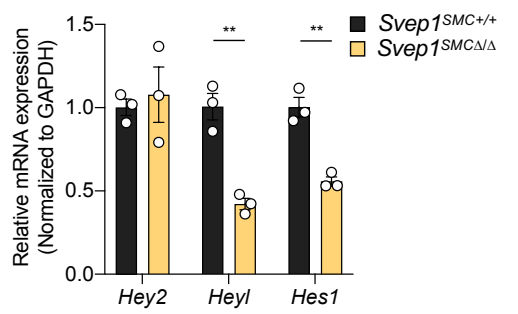

H

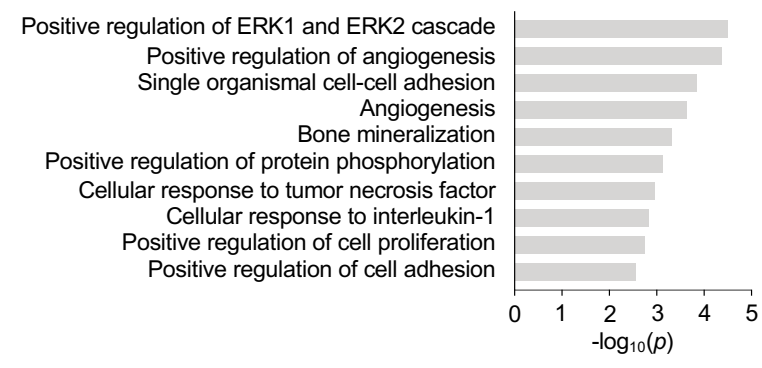

B

G

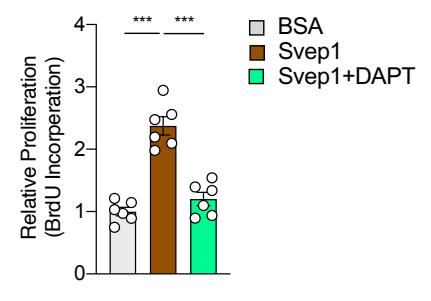

I

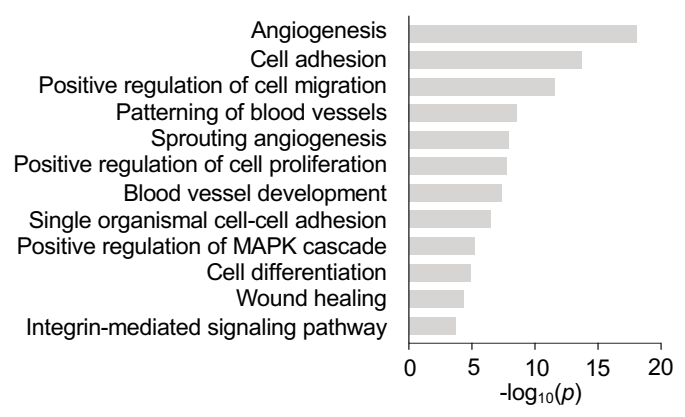

D
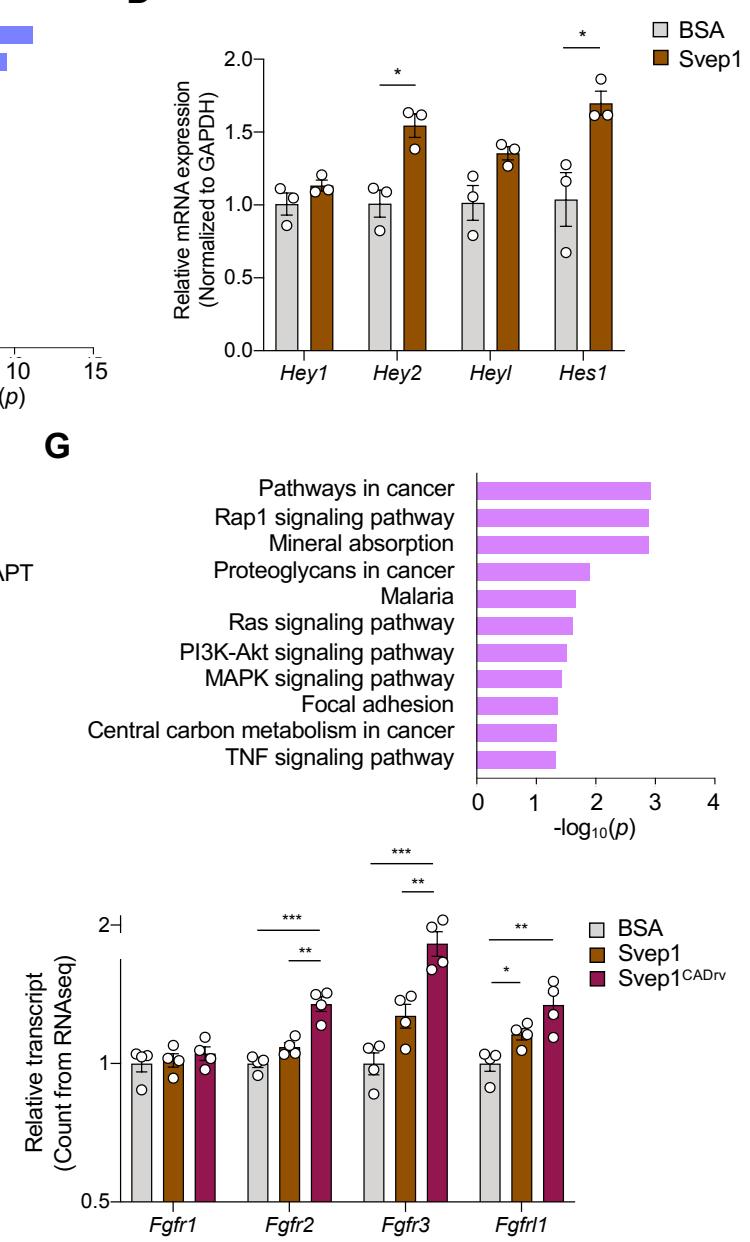

J

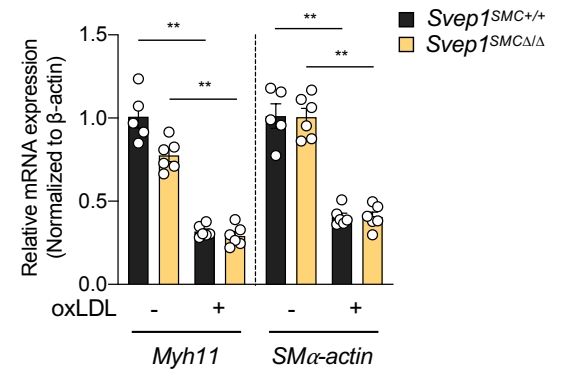

K

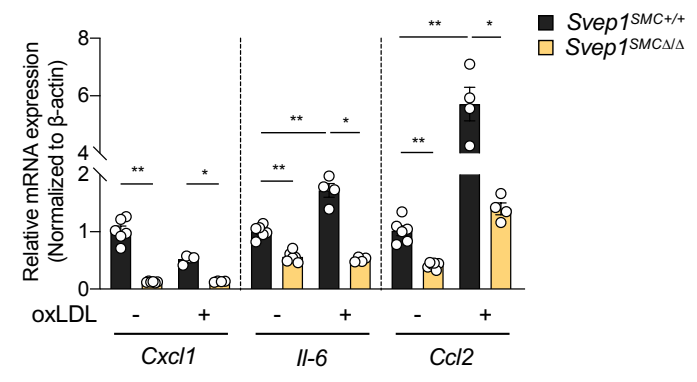




\section{Figure 7. Svep1 promotes inflammation in atherosclerosis}

A

Cytokine-cytokine receptor interaction Hematopoietic cell lineage Cell adhesion molecules (CAMs) Chemokine signaling pathway

B cell receptor signaling pathway

Osteoclast differentiation ECM-receptor interaction Complement and coagulation cascades

NF-kappa B signaling pathway

PI3K-Akt signaling pathway

Jak-STAT signaling pathway

TNF signaling pathway

Toll-like receptor signaling pathway

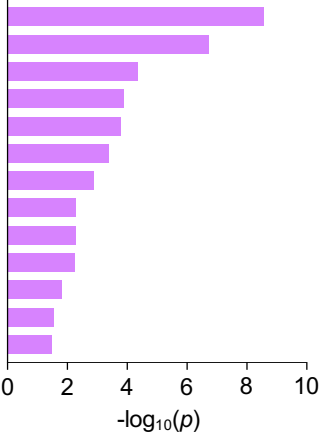

C

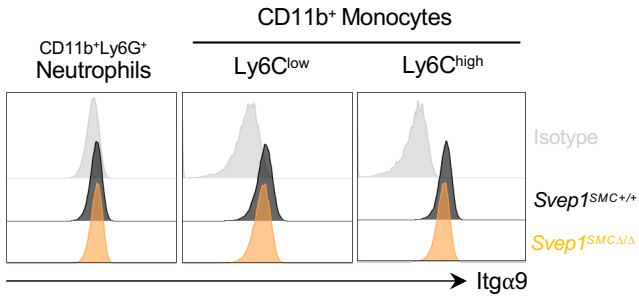

E

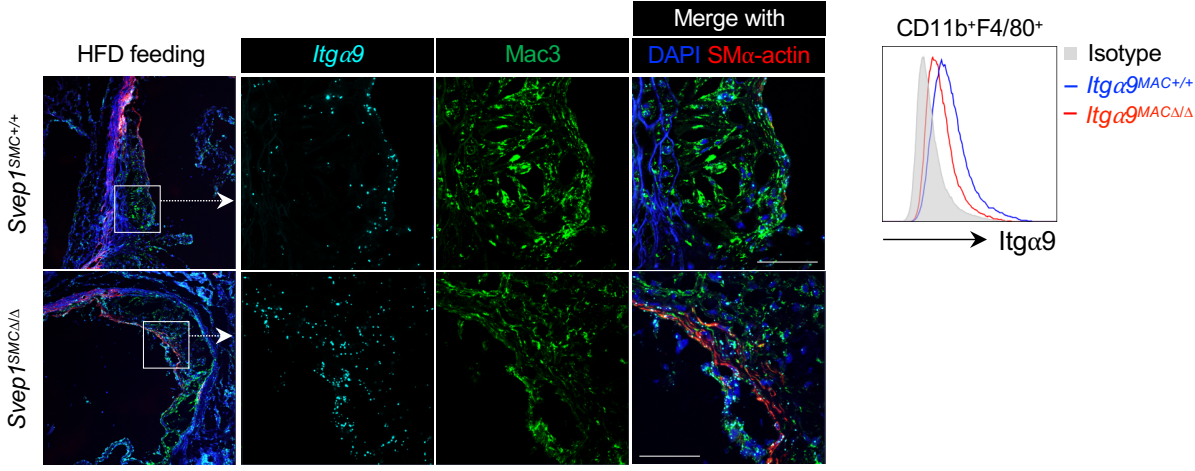

Immune system process Immune response Defense response Cell activation

Leukocyte activation

Inflammatory response

Innate immune response Regulation of cell activation Response to stress

Regulation of leukocyte activation Cytokine production Cell adhesion Biological adhesion Leukocyte migration Cell chemotaxis Leukocyte chemotaxis Cell migration

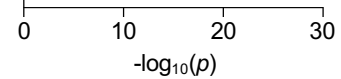

D

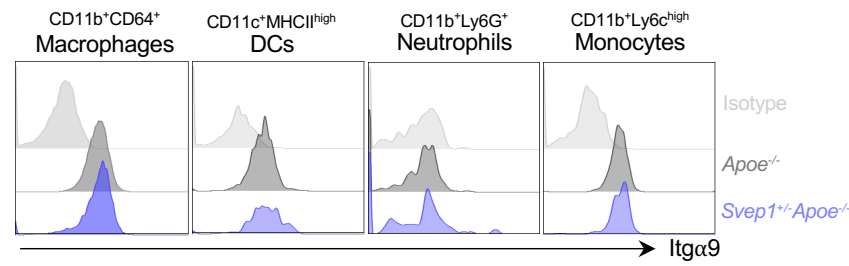

$\mathbf{F}$

G

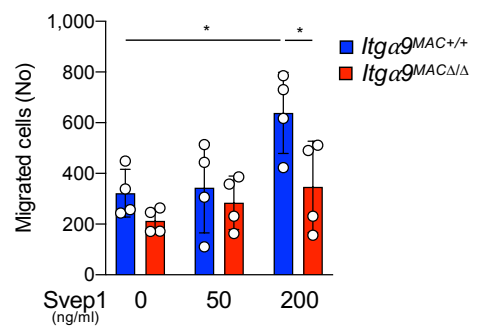

H

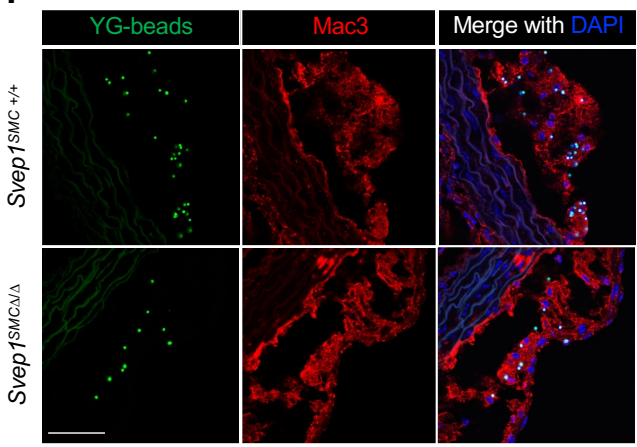

$\square$ Svep1SMC+/+ $\square$ Svep1SMCA/A

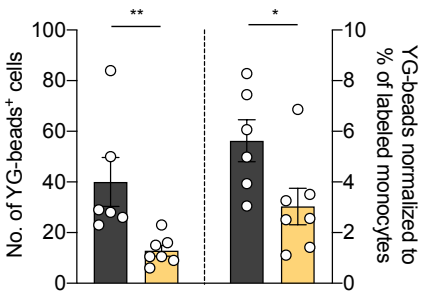




\section{Acknowledgements}

595 This work was supported in part by grants from the National Institutes of Health (NIH) T32GM007200 596 and T32HL134635 to JSE and NIH T32HL007081 to EPY, along with NIH grants R01HL131961, 597 UM1HG008853, UL1TR002345, an investigator-initiated research grant from Regeneron

598 Pharmaceuticals, a career award from the National Lipid Association, and by the Foundation for Barnes599 Jewish Hospital to NOS. We thank the Genome Technology Access Center in the Department of 600 Genetics at Washington University School of Medicine for help with genomic analysis. The Center is 601 partially supported by NCI Cancer Center Support Grant \#P30 CA91842 to the Siteman Cancer Center 602 and by ICTS/CTSA Grant\# UL1TR002345 from the National Center for Research Resources (NCRR), a 603 component of the National Institutes of Health, and NIH Roadmap for Medical Research. We thank the 604 Bursky Center for Human Immunology and Immunotherapy Programs at Washington University, 605 Immunomonitoring Laboratory for help with analysis of mouse plasma. This publication is solely 606 the responsibility of the authors and does not necessarily represent the official view of NCRR or NIH. 607 The Svep1 mouse strain used for this research was created from ES cell clone HEPD0747_6_B06, 608 generated by the European Conditional Mouse Mutagenesis Program which was then made into mice 609 and provided to the KOMP Repository (www.komp.org) by the Jackson Laboratory as part of the 610 KOMP2 Project. The Genotype-Tissue Expression (GTEx) Project was supported by the Common 611 Fund of the Office of the Director of the National Institutes of Health, and by NCI, NHGRI, NHLBI, 612 NIDA, NIMH, and NINDS. Data used for the analyses described in this manuscript were obtained from 613 the GTEx Portal on 04/30/2020. We thank all the members of the Stitziel Lab for helpful discussion.

\section{Author information}

616 NOS conceived of the study. IHJ performed animal experiments. JSE and IHJ performed in vitro 617 experiments. IHJ, JSE, AA, and NOS designed and interpreted the experiments. AA and KS generated 618 critical reagents. EPY and CJK performed Mendelian Randomization analyses. PK provided and 619 assisted with human specimens. KJL, BR, and RPM provided expertise in animal models and data 620 interpretation. IHJ, JSE, and NOS wrote the manuscript. All authors reviewed and provided critical 621 editing of the manuscript.

\section{Conflicts of interest}

624 NOS has received investigator-initiated research funds from Regeneron Pharmaceuticals. The other 625 authors have no conflicts. 


\section{Methods}

\section{Human tissue collection}

628 Prior to coronary artery bypass grafting surgery $(\mathrm{CABG})$ for the treatment of symptomatic coronary artery disease, we consented five patients for tissue and peripheral blood collection at the time of their 630 planned $\mathrm{CABG}$ to be performed at Barnes Jewish Hospital. The surgical plan for all patients included using the left internal mammary artery (LIMA) as an arterial graft to the left anterior descending (LAD) coronary artery and at least one venous graft to a different coronary artery. During the CABG, we collected the distal end of the LIMA which was trimmed in order to accommodate the length needed to reach the LAD. We also collected the aortic wall punch biopsy that was used to provide a proximal anastomotic site for the venous conduit. Tissues were immediately placed in phosphate buffered saline (PBS) on ice and brought to the laboratory where they were frozen at $-80^{\circ} \mathrm{C}$ prior to in situ hybridization described below. During the $\mathrm{CABG}$, we also collected $5-7 \mathrm{ml}$ of peripheral blood in a tube containing the anticoagulant $\mathrm{K}_{3}$ EDTA (\#6457, BD Biosciences) which was used for flow cytometry as described below. All research participants provided written informed consent and the study was approved by the Washington University School of Medicine Human Research Protection Office and Institutional Review Board.

\section{Mice}

All animal studies were approved by the Animal Studies Committee and the Institutional Animal Care and Use Committee of the Washington University School of Medicine. Svep ${ }^{+/-}$mice were made by KOMP (knockout mouse project), and these mice were then crossed with mice expressing the flippase FLP recombinase under the control of the promoter of the human actin beta gene (hATCB) to generate Svep $1^{\text {floxfflox }}\left(\right.$ Svep $\left.^{\Delta / \Delta}\right)$ mice. CRISPR/Cas9 genome editing technology was used in collaboration with the Washington University School of Medicine Genome Engineering and Transgenic Micro-Injection Cores to generate Svep $1^{G / G}$ mice on a C57BL/6 background harboring the SVEP1 mutation at the homologous murine position (p.D2699G). Svep $1^{+/-}$and Svep $1^{G / G}$ mice were crossed with Apoe ${ }^{-/-}$mice (\#002052, Jackson Laboratory) to get Svep $1^{+/-}$Apoe $^{-/}$and Svep $1^{G /+}{ }^{A p o e}{ }^{-/}$mice, which we maintained as breeders to generate experimental and control mice. We crossed Svep $1^{\Delta / \Delta}$ mice with Myh11-CreER ${ }^{T 2}$ (\#019079, Jackson Laboratory) mice to generate Svep $1^{\Delta /+}$ Myh11-CreER ${ }^{T 2}$ mice. Svep $1^{\Delta /+}$ Myh11CreER ${ }^{T 2}$ males were then crossed with Svep $1^{\Delta /+}$ females to generate experimental Svep $1^{\Delta / \Delta}$ Myhl1males were crossed with Apoe $e^{-/}$females. We maintained Svep $1^{\Delta /+}$ Myhl1-CreER ${ }^{T 2}$ Apoe $^{-/}$males and 
Svep $1^{\Delta /+}$ Apoe $^{-/-}$females as breeders to generate experimental Svep $1^{\Delta / \Delta}$ Myh11-CreER $R^{T 2}$ Apoe $^{-/-}$

$\left(\right.$ Svep $\left.1^{S M C \Delta / \Delta}\right)$ and control Myh11-CreER ${ }^{T 2}$ Apoe $^{-/}\left(\right.$Svep $\left.1^{S M C+/+}\right)$ mice. To activate Cre-recombinase, mice were injected intraperitoneally with $1 \mathrm{mg}$ of tamoxifen (\#T5648, Sigma-Aldrich) in $100 \mathrm{ml}$ peanut oil (\#P2144, Sigma-Aldrich) for 10 consecutive days starting at 6 weeks of age. Tamoxifen treatment was performed with all experimental and control mice in an identical manner. Itg $\alpha 9^{\text {flox } f \text { flox }}\left(\operatorname{Itg} \alpha 9^{\Delta / \Delta}\right)$ mice 663 were gifts from Dr. Dean Sheppard and Livingston Van De Water (Albany Medical College, New 664 York), and LysM-Cre mice were provided from Dr. Babak Razani (Washington University School of 665 Medicine, Saint Louis). We crossed Itg $\alpha 9^{f l / f l}$ mice with LysM-Cre mice to generate Itg $\alpha 9^{f l / f l}$ LysM-Cre $666\left(\operatorname{Itg} \alpha 9^{M A C \Delta / \Delta}\right)$ and control $\operatorname{Itg} \alpha 9^{+/+} \operatorname{LysM}-\operatorname{Cre}\left(\operatorname{Itg} \alpha 9^{M A C+/+}\right)$ mice. All mice were housed in separate cages 667 in a pathogen-free environment at Washington University School of Medicine animal facility and 668 maintained on a $12 \mathrm{hr}$ light/12 hr dark cycle with a room temperature of $22 \pm 1{ }^{\circ} \mathrm{C}$.

\section{Diet and assessment of atherosclerosis}

671 All experimental mice were fed a diet containing 21\% fat and 0.2\% cholesterol (\#TD.88137, Envigo

672 Teklad) for 8 and 16 weeks starting at 8 weeks of age. After HFD feeding, blood was collected from the retro-orbital plexus after $12 \mathrm{hr}$ of fasting. Mice were euthanized by carbon dioxide inhalation. Plasma samples were prepared from the collected blood by centrifugation at $13,000 \mathrm{rpm}$ for $10 \mathrm{~min}$ at $4^{\circ} \mathrm{C}$. Total cholesterol (\#STA-384), triglycerides (\#STA-397), and glucose (\#STA-681) in mouse plasma were determined using the appropriate kit (all purchased from Cell Biolabs, Inc). Hearts and whole aortas (from the aortic arch to the iliac artery) were harvested after perfusion with PBS. For en face analysis, isolated aortas were cleaned by removing perivascular fat tissues, opened longitudinally, and pinned onto black wax plates. After fixation with $4 \%$ paraformaldehyde overnight at $4{ }^{\circ} \mathrm{C}$, aortas were washed with PBS for $1 \mathrm{hr}$, and stained with $0.5 \%$ Oil Red O in propylene glycol (\#O1516, SigmaAldrich) for $3 \mathrm{hr}$ at room temperature. After staining, aortas were de-stained with 85\% propylene glycol in distilled water for 5 min to reduce background staining and washed with distilled water for 15 min. For analysis of plaque in aortic root, hearts were fixed overnight with $4 \%$ paraformaldehyde at $4{ }^{\circ} \mathrm{C}$, washed with PBS for $1 \mathrm{hr}$, and embedded into OCT compound (\#4583, Sakura ${ }^{\circledR}$ Finetek). 5- $\mu$ m-thick cryosections were stained overnight with $0.5 \%$ Oil Red O in propylene glycol, de-stained with $85 \%$ propylene glycol in distilled water for $5 \mathrm{~min}$, and washed with distilled water for $15 \mathrm{~min}$. Measurement of plaque was performed using 6-8 sections per artery to get the average value of size. The atherosclerotic plaque area was digitized and calculated using AxioVison (Carl Zeiss). 


\section{Antibodies and reagents}

691 To make the Svep1 protein, total RNA was purified from lung tissue of 8 week-old-mice by RNeasy ${ }^{\circledR}$ kit 692 (Life Technology). SuperScript IV First-Strand Synthesis System (Life Technology) with oligo d(T) $)_{20}$ 693 primer was used to obtain full-length reverse transcripts. Then, double strand DNA was synthesized by 694 PCR using PrimeSTAR GXL DNA Polymerase (Takara Bio) using forward 5'-

695 ATGTGGTCGCGCCTGGCCTTTTGTTG and reverse 5’-

AAGCCCGGCTCTCCTTTTCCTGGAACAATCAT primers, the amplicon was subcloned into pCMV6 plasmid (Origene Technology) in frame with Myc and Flag tag by In-Fusion HD EcoDry Cloning Plus System (Takara Bio). In order to insert a poly histidine tag for protein expression and purification, the Flag tag was replaced by a 10-histidine tag. Oligonucleotides 5'-

CACCACCACCACCACCACCACCACCACCACTGAACGGCCGG and 5'-

CCGTTCAGTGGTGGTGGTGGTGGTGGTGGTGGTGGTG coding for poly-histidine, stop codon and FseI compatible sticky end were synthetized, annealed and ligated to the vector, which was digested by EcoRV and FseI downstream of the myc tag and the stop codon respectively. The sequence of the full Svep1-myc-His 10 construct was verified by Sanger sequencing. The protein was expressed in FreeStyle $293 \mathrm{~F}$ cells (Invitrogen) grown in FreeStyle expression media. Transient transfection of the $3 \mu \mathrm{g} \mathrm{ml}^{-1}$ of vector DNA plus $9 \mu \mathrm{g} \mathrm{ml}^{-1}$ Polyethylenimine (PEI) (25 kDa linear PEI, Polysciences, Inc.) was used to express the protein in $2.5 \times 10^{6}$ cells ml-1 . After overnight incubation, the same volume of fresh media plus $1 \mathrm{mM}$ (final concentration) valproic acid was added. The transfected cells were incubated in flasks in orbital shaker at $100 \mathrm{rpm}$ in $37^{\circ} \mathrm{C}$ with $8 \% \mathrm{CO}_{2}$ incubator for $48 \mathrm{hr}$, the conditioned media was collected by centrifugation at $300 \mathrm{rpm}$ for $15 \mathrm{~min}$. Cells were resuspended in fresh expression media and incubated for $48 \mathrm{hr}$. The conditioned media was collected, and this procedure was repeated one more time. Cell viability at the end of the experiment was $>70 \%$. The protein was purified in a NGC chromatographic system (BioRad Lab) in two steps: i) conditioned media was added to $1 / 10$ of its volume of 10X PBS, and the $\mathrm{pH}$ check and fixed to 7.1. The protein was pulled down by a disposable column loaded with $5 \mathrm{ml}$ Nuvia IMAC resin (BioRad Lab) at $1 \mathrm{ml} \mathrm{min}^{-1}$, washed with $50 \mathrm{ml}$ PBS and the protein eluted in PBS plus $250 \mathrm{mM}$ Imidazole, and ii) the eluted protein solution was concentrated 10 times in a Vivaspin concentrator $30 \mathrm{kDa}$ cut off and loaded in a Superose 6 increase 10/300 (GE Life Sciences) with PBS as a carrier buffer. The fractions were evaluated by western blot probed with Myc tag antibody, and the purity of the protein was evaluated in PAGE-SDS 4-15\% stained with Coomassie brilliant blue. More of the $95 \%$ of the protein in the gel corresponded to a single band. Further analysis by Mass Spectroscopy confirmed that more than $95 \%$ of the peptides detected corresponded to Svep1. 
For immunofluorescent staining, anti- $\beta$-galactosidase (\#ab9361, abcam, 1:1000), anti-Mac3 723 (\#550292, clone M3/84, BD Biosciences, 1:100), anti-SM $\alpha$-actin-cy3 (\#C6198, clone 1A4, Sigma724 Aldrich, 1:1000), anti-MCM-2 (\#4007, Cell Signaling, 1:100) were used, and then visualized with anti725 chicken-Alexa488 (\#A11039), anti-rat-Alexa488 (\#A21470), anti-rat- Alexa594 (\#A21471, all 726 purchased from Invitrogen, 1:400), and ProLong ${ }^{\mathrm{TM}}$ Gold antifade reagent with DAPI (\#P36935, 727 Invitrogen) were used. In case of detection of MCM-2 staining, samples were visualized with anti728 rabbit-HRP (\#7074S, Cell Signaling, 1:1000) followed by TSA ${ }^{\circledR}$ Plus Cyanine 5 (\#NEL745E001KT, 729 PerkinElmer). For immunohistochemistry study, hematoxylin solution (\#HHS80), eosin solution 730 (\#HT110180), Masson's trichrome staining kit (\#HT15-1KT, all purchased from Sigma-Aldrich), and 731 Permount solution (\#SP15-500, Fisher Chemicals) were used. For flow cytometry, following anti-mouse 732 antibodies were used; anti-CD16/32 FcR blocker (\#14-0161, eBioscience), PerCP-labeled anti-CD45 733 (\#103129, clone 30-F11), BV510-labeled anti-CD11b (\#101263, clone M1/70), BV421-labeled anti734 CD64 (\#139309, clone X54-5/7.1), PE/cy7-labeled anti-CD11c (\#117317, clone N418), APC/cy7735 labeled anti-MHCII (\#107627, clone M5/114.15.2), FITC-labeled anti-F4/80 (\#123108, clone BM8), 736 BV605-labeled anti-CD19 (\#115540, clone 6D5), APC-labeled anti-CD115 (\#135510, clone AFS98), 737 Alexa700-labeled anti-Ly6C (\#128023, clone HK1.4), PE/Cy7-labeled anti-Ly6G (\#127618, clone 1A8, 738 all purchased from Biolegend), PE/cy5.5-labeled anti-CD4 (\#35-0042-82, clone RM4-5, eBioscience), 739 Alexa700-labeled anti-CD8a (\#56-0081-80, clone 53-6.7, eBioscience), and PE-labeled anti-Itg $\alpha 9 \beta 1$ 740 (\#FAB3827P, R\&D systems). Following anti-human antibodies were used. FcR blocker (\#564219, BD 741 biosciences), PerCP/cy5.5-labeled anti-CD45 (\#368504, clone 2D1), Alexa700-labeled anti-CD3 742 (\#300323, clone HIT3a), anti-CD19 (\#115527, clone 6D5), anti-CD56 (\#392417, clone QA17A16), 743 FITC-labeled anti-CD15 (\#301904, clone HI98), BV421-labeled CD66b (\#305111, clone G10F5), 744 APC/cy7-labeled anti-CD14 (\#325619, clone HCD14), BV605-labeled anti-CD16 (\#360727, clone 745 B73.1), and PE-labeled anti-ITGa9ß1 (\#351606, clone Y9A2, all purchased from Biolegend). RBC lysis 746 buffer (\#423101, Biolegend), FoxP3 transcription factor staining buffer set (\#00-5523, eBioscience), 747 Leuko spin medium (\#60-00091, Pluriselect) were used in flow cytometry experiments. Antibodies for 748 western blotting include: Src (\#2109), P-Src (\#6943) FAK (\#3285), P-FAK (\#8556), Paxillin (\#2542), P749 Paxillin (\#2541), Erk (\#4695), P-Erk (\#4370), p38 (\#8690), P-p38 (\#9211, all purchased from Cell 750 signaling Technologies). 


\section{Immunohistochemistry and immunofluorescent staining}

753 For all immunohistochemistry and immunofluorescent study, we used 4\% paraformaldehyde-fixed 754 frozen sections with 5- $\mu \mathrm{m}$-thickness. For immunofluorescent staining, slides were air-dried for $1 \mathrm{hr}$ at room temperature and hydrated with PBS for $10 \mathrm{~min}$. After permeabilization with $0.5 \%$ tritonX-100 for 10 min, sections were blocked with PBS containing 5\% chicken serum (\#S-3000, Vector Laboratories) with $0.5 \%$ tritonX-100 for $1 \mathrm{hr}$ at room temperature. And then slides were incubated with the indicated antibodies. For hematoxylin and eosin (H\&E) staining, air-dried slides were hydrated in PBS for $10 \mathrm{~min}$, placed in hematoxylin solution for $10 \mathrm{~min}$, and then rinsed in running tap water. After de-staining in $1 \%$ acetic acid for $5 \mathrm{~min}$, slides were rinsed in tap water, and placed in 90\% ethanol for $5 \mathrm{~min}$. Slides were stained with eosin solution for $8 \mathrm{~min}$, gradually dehydrated in ethanol solution (from $80 \%$ to $100 \%$ ), and then incubated with xylene for 10 min followed by mounting with Permount solution. For Masson's trichrome staining, air-dried slides were hydrated in distilled water for $10 \mathrm{~min}$, placed in Mordant in Bousin's solution for $1 \mathrm{hr}$ at $56^{\circ} \mathrm{C}$, and rinsed in running tap water for $5 \mathrm{~min}$. After staining in hematoxylin solution for $10 \mathrm{~min}$, slides were washed in running tap water for $10 \mathrm{~min}$, rinsed in distilled water, placed in Biebrich scarlet-acid fuchsin solution for $15 \mathrm{~min}$, and stained in aniline blue solution for 10 min. After rinsing in distilled water, slides were differentiated in 1\% acetic acid for 3 min, gradually dehydrated in ethanol solution (from $80 \%$ to $100 \%$ ), incubated with xylene for 10 min followed by mounting with Permount solution.

\section{RNAscope in situ hybridization (ISH)}

772 For detection of Svep 1, Itg $\alpha 9$ RNA transcripts in both human and mouse artery tissues, a commercially available kit (\#323100, RNAscope ${ }^{\circledR}$ Multiplex Fluorescent Reagent Kit v2, Advanced Cell Diagnostics) was used according to the manufacturer's instructions. Briefly, $4 \%$ paraformaldehyde-fixed mouse aortic root and human aortic wall, and LIMA frozen sections with 5- $\mu \mathrm{m}$-thickness were air-dried for $1 \mathrm{hr}$ at room temperature, and treated with hydrogen peroxide for $10 \mathrm{~min}$ to block endogenous peroxidase activity. After antigen retrieval by boiling in target antigen retrieval solution for $5 \mathrm{~min}$ at $95-100^{\circ} \mathrm{C}$, slides were treated with protease III for $30 \mathrm{~min}$ at $40^{\circ} \mathrm{C}$. Target probes (\#406441, mouse Svep 1; \#540721, mouse Itga9; \#811671, human SVEP1; \#811681, human ITGA9) were hybridized for $2 \mathrm{hr}$ at $40^{\circ} \mathrm{C}$, followed by a series of signal amplification and washing steps. Hybridization signals were detected by TSA ${ }^{\circledR}$ Plus Cyanine 5, and co-stained with indicated antibodies. Slides were counterstained with DAPI by using ProLong ${ }^{\mathrm{TM}}$ Gold antifade reagent. 


\section{Flow cytometry}

785 For labeling mouse blood cells, blood was collected from the retro-orbital plexus, and red blood cells

786 were removed using RBC lysis buffer (\#00-4300-54, eBioscience). For labeling human blood cells,

787 Leuko spin medium (Pluriselect) was used to isolate leukocytes from peripheral blood and buffy coat. In

788 an experiment using mouse spleen, spleen cells were recovered from mice by cutting the spleen into

789 small fragments, and incubated with $400 \mathrm{U}$ collagenase D (\#11-088-858, Roche applied science) for 30

$790 \mathrm{~min}$ at $37^{\circ} \mathrm{C}$. For labeling aortic single cell suspensions, isolated aortas were perfused with DPBS, and

791 opened longitudinally. The whole artery was cut into $2-5 \mathrm{~mm}$ pieces, and incubated in a Hanks'

792 Balanced Salt Solution (HBSS) solution with calcium and magnesium containing $90 \mathrm{U} \mathrm{ml}^{-1} \mathrm{DNase} \mathrm{I}$

793 (\#DN25), $675 \mathrm{U} \mathrm{ml}^{-1}$ collagenase I (\#C0130), $187.5 \mathrm{U} \mathrm{ml}^{-1}$ collagenase XI (\#C7657), and $90 \mathrm{U} \mathrm{ml}^{-1}$

794 hyaluronidase (\#H1 115000, all purchased from Sigma-Aldrich) for $70 \mathrm{~min}$ at $37{ }^{\circ} \mathrm{C}$ with gentle shaking.

795 Non-specific binding to Fc receptors was blocked, and cells were incubated with the indicated

796 antibodies for $30 \mathrm{~min}$ at $4^{\circ} \mathrm{C}$. For intracellular staining, cells were fixed/permeabilized with the FoxP3

797 transcription factor staining buffer set. Flow cytometric analyses were performed using LSRFortessa ${ }^{\mathrm{TM}}$

798 instrument (BD Biosciences) and FlowJo software (Tree Star Inc).

\section{Bead labeling of $\mathrm{Ly}^{\mathrm{low}}$ monocytes recruited into atherosclerotic plaque}

801 After 8 weeks of HFD feeding, $200 \mu \mathrm{L}$ of $1 \mu \mathrm{m}$ Fluoresbrite yellow-green (YG) microspheres beads 802 (\#17154-10, Polysciences, Inc) diluted 1:4 in sterile DPBS were administered retro-orbitally. Labeling 803 efficiency of blood monocytes was verified by flow cytometry 3 days after YG bead injection.

804 Recruitment of YG-beads positive monocytes into plaque in aortic root was analyzed 1 day after 805 checking labeling efficiency of YG beads. 5- $\mu \mathrm{m}$-thick frozen sections of aortic root were stained with 806 anti-Mac3, followed by anti-rat-Alexa594 antibody. And slides were mounted with ProLong ${ }^{\mathrm{TM}}$ Gold 807 Antifade Mountant with DAPI. The number of YG-beads colocalized with Mac3 positive area was 808 counted, or normalized with the percentages of labeled Ly6 $\mathrm{C}^{\text {low }}$ monocytes.

\section{Aortic VSMC culture}

811 Mouse aortic VSMCs were isolated from 8-week-old Apoe ${ }^{-/}$and Svep 1 ${ }^{+/-}$Apoe ${ }^{-/-}$, or same age of 812 Svep $1^{S M C+/+}$ and Svep $1^{S M C \Delta / \Delta}$ mice after tamoxifen injection for 10 consecutive days starting at 6 weeks of 813 age. Briefly, thoracic aortas were harvested (3 mice per group were used), perivascular fat was removed, 814 and then aortas were digested in $1 \mathrm{mg} \mathrm{ml}^{-1}$ collagenase II (\#LS004174), 0.744 units ml$^{-1}$ elastase 815 (\#LS002279), $1 \mathrm{mg} \mathrm{ml}^{-1}$ soybean trypsin inhibitor (\#LS003570, all purchased from Worthington 
816 Biochemical Corporation), and 1\% penicillin/streptomycin in $\mathrm{HBSS}$ for 10 min at $37^{\circ} \mathrm{C}$ with gentle

817 shaking. After a pre-digestion with enzyme mixture, the adventitial layer was removed under the

818 dissection microscope, and the intimal layer was removed by scrapping with forceps. Aortas were cut

819 into small pieces, and completely digested in enzyme mixture at $37^{\circ} \mathrm{C}$ for $1 \mathrm{hr}$ with gentle shaking.

820 VSMCs were grown in 20\% fetal bovine serum (FBS, Hyclone) containing Dulbecco modified Eagle

821 medium/F12 (DMEM/F12) media (Gibco) with $100 \mathrm{U} \mathrm{ml}^{-1}$ penicillin/streptomycin at $37^{\circ} \mathrm{C}, 5 \% \mathrm{CO}_{2}$

822 incubator. After 2 passages, VSMCs were changed to $10 \%$ serum. To stimulate VSMCs, $50 \mu \mathrm{g} \mathrm{ml}{ }^{-1}$

823 human medium oxidized low density lipoprotein (oxLDL, \#770202-7, Kalen biomedical) was used.

\section{Quantitative real time PCR}

826 Gene expression was quantified by quantitative real time PCR. RNA was isolated using RNeasy® Mini 827 Kit (\#74106, Qiagen) according to manufacturer's protocol, and QIAshredder homogenizer (\#79656, 828 Qiagen) to increase yield of quantification of RNA. cDNA was synthesized with High Capacity cDNA 829 Reverse Transcript Kit (\#4368814). Real time PCR was performed using both Taqman ${ }^{\circledR}$ (\#4444557) and 830 SYBR ${ }^{\mathrm{TM}}$ Green (\#A25742, all purchased from Applied Biosystems) assays. Ct values were normalized 831 to $\beta$-actin (for Taqman ${ }^{\circledR}$ ) and gapdh (for SYBR ${ }^{\mathrm{TM}}$ Green), and showed as expression relative to control. 832 List of probes and primers used are in Supplemental Table 3.

\section{In vitro migration assay using peritoneal macrophage}

$835 \operatorname{Itga}^{M A C+/+}$ and $\operatorname{Itga} 9^{M A C \Delta / \Delta}$ mice were injected intraperitoneally with $1 \mathrm{ml} 4 \%$ thioglycolate. After 5 836 days, the peritoneal cells were collected by lavage and placed in RPMI media containing 10\% FBS for $83760 \mathrm{~min}$ at $37^{\circ} \mathrm{C}$. Non-adherent cells were removed after washing with PBS for 3 times, and adherent 838 cells (more than $90 \%$ were peritoneal macrophages confirmed by flow cytometry) were placed in Trans839 well inserts with a 5- $\mu \mathrm{m}$ porous membrane in a modified Boyden chamber. RPMI media containing $84010 \%$ FBS with 50 or $200 \mathrm{ng} \mathrm{ml}^{-1}$ Svep1 protein was placed in the lower chamber. After allowing cell 841 migration of $16 \mathrm{hr}$, inserts were removed from upper sider of the chamber, and nuclei of migrated cells 842 to the lower side of the membrane were stained with DAPI. The number of migrated cells 843 was determined by In Cell Analyzer 2000 (GE healthcare).

\section{Proliferation and adhesion assays}

846 Wells of a 96 well plate were pre-coated with $30 \mu \mathrm{g} \mathrm{ml}^{-1}$ recombinant Svep1 protein or bovine serum albumin (BSA, as an inert protein control). Wells were subsequently blocked with $10 \mathrm{mg} \mathrm{ml}^{-1} \mathrm{BSA}$ and 
washed twice with DPBS. Plates were ultraviolet (UV) sterilized before adding cells. For proliferation assays, primary VSMCs were collected and suspended in DMEM/F12 media containing 10\% FBS. 2,000 cells were added to each well and incubated for $8 \mathrm{hr}$ to assure complete cell adhesion. Media was then replaced with DMEM/F12 media containing 0.2\% BSA and incubated for $12 \mathrm{hr}$ to reduce basal proliferation rates. Cells were then incubated in BrdU dissolved in DMEM/F12 media containing 0.2\% BSA for $30 \mathrm{hr}$. Predesigned Silencer Select siRNA constructs targeting Itg $\alpha 9$ and negative control siRNA were obtained from ThermoFisher. Primary VSMCs were transfected using RNAiMAX transfection reagents according to the manufacturer's protocol. Efficient $\operatorname{Itg} \alpha 9$ knockdown was confirmed by qPCR. Cells were trypsinized $24 \mathrm{hr}$ after transfection and used for the proliferation assay. DAPT or DMSO (carrier) were added to cells throughout the indicated experiment at a concentration of $25 \mu \mathrm{M}$. For using peritoneal macrophages, 4\% thioglycolate-elicited peritoneal macrophages from $\operatorname{Itg} \alpha 9^{M A C+/+}$ and $\operatorname{Itg} \alpha 9^{M A C A / \Delta}$ mice were suspended in BrdU-containing RPMI 1640 media that also contained 10\% FBS. 25,000 cells were added to each well since peritoneal macrophages have lower proliferation rates than VSMCs in culture. $50 \mu \mathrm{g} \mathrm{ml}^{-1}$ oxLDL was added to the indicated cells at the beginning of this incubation. An ELISA for incorporated BrdU was then performed using kit instructions (\#6813, Cell Signaling Technologies) after incubation for $36 \mathrm{hr}$. Adhesion assays were performed in precoated 96-well plates blocked with $100 \mathrm{mg} \mathrm{ml}^{-1}$ BSA. Blocking conditions were empirically derived to minimize non-specific cell adhesion. After a 5 (for THP-1 cells) or 15 (for VSMCs) min incubation, non-adhered cells were removed by gently centrifuging the plates upside down. VSMCs were counted manually and THP-1 cells were counted by automated microscopy after staining cells with DAPI.

\section{Western blotting assay}

Cells were resuspended in serum free media (SFM), and incubated with gentle agitation to prevent cell attachment and reduce basal signaling. Cells were washed with SFM then seeded on BSA-blocked plates coated with either BSA, VCAM-1, Svep1, or Svep1 ${ }^{\text {CADrv }}$. Concentrations of VCAM-1 and Svep1 were derived empirically to prevent signal saturation. BSA concentrations always matched the Svep1 concentration. It is only appropriate, therefore, to compare between BSA, Svep1, and Svep1 CADrv groups. Cells were briefly centrifuged to the bottom of the wells and incubated for 8 min (for VSMCs) or 15 min (for THP-1 cells) before lysis with cell lysis buffer (\#9803, Cell Signaling Technologies) containing a cocktail of protease and phosphatase inhibitors. Western blots were performed by standard techniques, as briefly follows. Protein content was determined using a bicinchoninic acid assay with 
BSA standards (\#23225, Pierce ${ }^{\mathrm{TM}}$ BCA Protein Assay Kit). Cell lysates were then reduced with DTT in

881 lithium dodecyl sulfate sample buffer (\#NP0007, Invitrogen). Equal protein amounts were added to

882 polyacrylamide gels (\#4561086, BioRad) and electrophoresed prior to transferring to a nitrocellulose or 883 polyvinylidene fluoride membrane (\#1620260, BioRad). Membranes were blocked in 5\% BSA/Tris884 Buffered Saline with tween 20 for $30 \mathrm{~min}$. The indicated primary antibodies were incubated with the 885 pre-blocked membranes for overnight at $4^{\circ} \mathrm{C}$. Membranes were washed with Tris-Buffered Saline with tween 20 , probed with fluorescent secondary antibodies, and imaged. $\beta$-actin or $\beta$-tubulin served as a loading control.

\section{Bulk RNA sequencing and analysis}

Primary VSMCs were plated on wells precoated with $30 \mu \mathrm{g} \mathrm{ml}^{-1}$ recombinant Svep1, Svep1 ${ }^{\text {CADrv }}$ protein or BSA (as an inert protein control). Wells were subsequently blocked with $10 \mathrm{mg} \mathrm{ml}^{-1} \mathrm{BSA}$ and washed twice with DPBS. Plates were UV sterilized before adding cells. Primary VSMCs were collected, resuspended in DMEM/F12 media containing 10\% FBS, plated on precoated, blocked wells, and incubated for $8 \mathrm{hr}$ to ensure complete cell adhesion. Media was replaced with fresh DMEM/F12 containing 1\% FBS and incubated for $12 \mathrm{hr}$ before collection. RNA was collected using RNeasy® Mini Kit (\#74106, Qiagen). Atherosclerotic aortic arches (including the aortic root, arch, and the proximal regions of its branching vessels) from mice were used as the source of RNA for the later RNAseq experiment. These tissues were isolated and separated from the perivascular adipose prior to storing in RNAlater (\#AM7021, Thermofisher) prior to total RNA extraction using nucleoZOL (Macherey-Nagel). cDNA for validation was synthesized with High Capacity cDNA Reverse Transcript Kit (\#4368814, Applied Biosystems), following standard protocols.

Samples were prepared according to library kit manufacturer's protocol, indexed, pooled, and sequenced on an Illumina HiSeq. Basecalls and demultiplexing were performed with Illumina's bcl2fastq software and a custom python demultiplexing program with a maximum of one mismatch in the indexing read. RNA-seq reads were then aligned to the Ensembl release 76 primary assembly with STAR version 2.5.1a (Dobin et al., 2013). Gene counts were derived from the number of uniquely aligned unambiguous reads by Subread:featureCount version 1.4.6-p5 (Liao et al., 2014). Isoform expression of known Ensembl transcripts were estimated with Salmon version 0.8.2 (Patro et al., 2017). Sequencing performance was assessed for the total number of aligned reads, total number of uniquely aligned reads, and features detected. The ribosomal fraction, known junction saturation, and read distribution over known gene models were quantified with RSeQC version 2.6.2 (Wang et al., 2012). All gene counts 
912 were then imported into the R/Bioconductor package EdgeR (Robinson et al., 2010) and TMM

913 normalization size factors were calculated to adjust for samples for differences in library size.

914 Ribosomal genes and genes not expressed in the smallest group size minus one sample greater than one 915 count-per-million were excluded from further analysis. The TMM size factors and the matrix of counts 916 were then imported into the R/Bioconductor package Limma (Ritchie et al., 2015). Weighted likelihoods 917 based on the observed mean-variance relationship of every gene and sample were then calculated for all 918 samples with the voomWithQualityWeights (Liu et al., 2015). The performance of all genes was 919 assessed with plots of the residual standard deviation of every gene to their average log-count with a 920 robustly fitted trend line of the residuals. Differential expression analysis was then performed to analyze 921 for differences between conditions and the results were filtered for only those genes with Benjamini922 Hochberg false-discovery rate adjusted $P$-values less than or equal to 0.05 . One sample in the aortic arch 923 experiment was independently identified as an outlier by standard quality control methods. This group was excluded from downstream analyses.

$925 \quad$ For each contrast extracted with Limma, global perturbations in known Gene Ontology (GO)

926 terms, KEGG pathways, and InterPro domains were detected using the Database for Annotation, 927 Visualization and Integrated Discovery (DAVID) (Huang da et al., 2009) on significantly dysregulated 928 transcripts or using the R/Bioconductor package GAGE (Luo et al., 2009) to test for changes in 929 expression of the reported $\log 2$ fold-changes reported by Limma in each term versus the background $930 \log 2$ fold-changes of all genes found outside the respective term. The R/Bioconductor package 931 heatmap3 (Zhao et al., 2014) was used to display heatmaps across groups of samples for each GO or $932 \mathrm{MSigDb}$ term with a Benjamini-Hochberg false-discovery rate adjusted p-value less than or equal to 933 0.05. Perturbed KEGG pathways where the observed $\log 2$ fold-changes of genes within the term were 934 significantly perturbed in any direction compared to other genes within a given term with $P$-values less 935 than or equal to 0.05 were rendered as annotated KEGG graphs with the R/Bioconductor package 936 Pathview (Luo and Brouwer, 2013).

\section{Notch signaling assays}

939 Cells were collected, resuspended in SFM, and incubated for $1 \mathrm{hr}$ with gentle agitation before seeding on 940 tissue culture wells that were precoated and blocked, as described in previous sections. Cells were 941 collected for analysis after $4 \mathrm{hr}$ of growth on the indicated substrate. Svep $1^{\text {SMC+/+ }}$ and Svep $1^{\text {SMCA/A }}$ 942 VSMCs were collected for analysis after $72 \mathrm{hr}$ of incubation in SFM to obtain basal Notch signaling. 943 Notch target gene primers used for the qPCR are listed in Supplementary Table 3. 
945 Analysis of cytokine and chemokine biomarkers

946 MILLIPLEX MAP Mouse Cytokine/Chemokine Magnetic Bead Panel-Immunology Multiplex Assay 947 (\#MCYTOMAG-70K), MILLIPLEX MAP Mouse Angiogenesis/Growth Factor Magnetic Bead Panel948 Cancer Multiplex Assay (\#MAGPMAG-24K), and MILLIPLEX MAP Mouse Cardiovascular Disease 949 (CVD) Magnetic Bead Panel 1-Cardiovascular Disease Multiplex Assay (\#MCVD1MAG-77K-02, all 950 from Millipore Sigma) were used to analyze cytokines and chemokines from mouse plasma. All kits 951 were used according to manufacturer recommended protocols. Briefly, the Luminex FLEXMAP 3D ${ }^{\circ}$ 952 (Luminex Corporation, Austin, TX) instrument was used to sort the magnetic polystyrene beads and 953 measure the phycoerythrin (PE) tagged detection antibody signal. Fifty beads from each analyte were 954 measured. The median fluorescent intensity (MFI) was compared against the standard curve to calculate 955 the pg ml-1 or $\mathrm{ng} \mathrm{ml}^{-1}$ using Milliplex Analyst 5.1 software (VigeneTech.com) and a 5-parameter logistic 956 curve fit algorithm.

\section{BMDM isolation and culture}

959 6- to 8-week-old $\operatorname{Itg} \alpha 9^{M A C+/+}$ and $\operatorname{Itg} \alpha 9^{M A C \Delta / \Delta}$ mice were euthanized by carbon dioxide inhalation, and 960 soaked in 75\% ethanol. Then, femurs and tibias were harvested and bone-marrow cells were obtained by 961 flushing bones and differentiated for 7 days in DMEM media supplemented with $50 \mathrm{mg} \mathrm{ml}^{-1}$ 962 recombinant macrophage-colony stimulating factor (M-CSF, R\&D systems), 20\% heat-inactivated FBS, 963 and antibiotics.

\section{Mendelian Randomization}

966 To estimate the causal effect of SVEP1 plasma protein levels on risk of CAD, hypertension, and type 2 967 diabetes (T2D), we performed Mendelian Randomization using summary statistics from publicly 968 available datasets. Genome-wide summary statistics for risk of CAD were obtained from a meta-analysis 969 of CAD using data from CARDIoGRAMPlusC4D and the UK Biobank as previously described (van der 970 Harst and Verweij, 2018). Genome-wide summary statistics for hypertension and T2D were obtained 971 from the IEU GWAS database (Hemani et al., 2018) using association results from the UK Biobank. 972 Summary statistics for primary hypertension (ICD 10 code I10) as a secondary diagnosis (IEU GWAS 973 ID "ukb-b-12493") were used for hypertension while summary statistics for diabetes diagnosed by a 974 doctor (IEU GWAS ID “ukb-b-10753") were used for T2D. 
A genome-wide association study to identify protein quantitative trait loci using a SomaLogic

976 aptamer-based protein assay has previously been described (Sun et al., 2018). Two aptamers

977 (SVEP1.11109.56.3 and SVEP1.11178.21.3) were used to estimate SVEP1 protein concentration. We 978 obtained genome-wide summary statistics for both aptamers which produced highly similar results; for 979 simplicity, results from the analysis using the SVEP1.11178.21.3 aptamer were reported. As trans980 pQTLs might affect protein levels in a variety of manners, we focused our analysis on cis-pQTLs by 981 only including variants in a $1 \mathrm{Mb}$ window surrounding SVEP1 which associated with plasma SVEP1 982 concentration at a level exceeding genome-wide significance ( $P$-value for SVEP1 concentration $<5 \times$ $\left.98310^{-8}\right)$. We filtered these SNPs using pair-wise linkage disequilibrium estimated from the 1000 Genomes 984 Project European samples in order to obtain an independent $\left(\mathrm{r}^{2}<0.3\right)$ set of SNPs for the causal 985 analysis. Causal estimates were calculated using the inverse-variant weighted method implemented in 986 the R package TwoSampleMR (Hemani et al., 2017; Hemani et al., 2018).

988 Statistical analysis

989 For animal model data, a two-group independent t-test, one-way analysis of variance (ANOVA), or two990 way ANOVA were used, provided the data satisfied the Shapiro-Wilk normality test. Otherwise, the 991 Mann-Whitney U test, Kruskal-Wallis one-way ANOVA test, and Friedman two-way ANOVA test were 992 used. Bonferroni correction was used for post-hoc multiple comparison in ANOVA. Unless otherwise 993 stated, cellular assays were analyzed by an unpaired, two-tailed t-test. Statistical analyses were 994 performed with GraphPad Prism. 


\section{References}

Andrews, M.R., Czvitkovich, S., Dassie, E., Vogelaar, C.F., Faissner, A., Blits, B., Gage, F.H., ffrenchConstant, C., and Fawcett, J.W. (2009). Alpha9 integrin promotes neurite outgrowth on tenascin-C and enhances sensory axon regeneration. J Neurosci 29, 5546-5557.

Ayari, H., and Bricca, G. (2013). Identification of two genes potentially associated in iron-heme homeostasis in human carotid plaque using microarray analysis. J Biosci 38, 311-315.

Basatemur, G.L., Jorgensen, H.F., Clarke, M.C.H., Bennett, M.R., and Mallat, Z. (2019). Vascular smooth muscle cells in atherosclerosis. Nature reviews Cardiology 16, 727-744.

Bennett, M.R., Sinha, S., and Owens, G.K. (2016). Vascular Smooth Muscle Cells in Atherosclerosis. Circulation research 118, 692-702.

Boucher, J., Gridley, T., and Liaw, L. (2012). Molecular pathways of notch signaling in vascular smooth muscle cells. Front Physiol 3, 81.

Burgess, S., Scott, R.A., Timpson, N.J., Davey Smith, G., Thompson, S.G., and Consortium, E.-I. (2015). Using published data in Mendelian randomization: a blueprint for efficient identification of causal risk factors. European journal of epidemiology 30, 543-552.

C Baigent, A.K., P M Kearney, L Blackwell, G Buck, C Pollicino, A Kirby, T Sourjina, R Peto, R Collins, R Simes, Cholesterol Treatment Trialists' (CTT) Collaborators (2005). Efficacy and Safety of CholesterolLowering Treatment: Prospective Meta-Analysis of Data From 90,056 Participants in 14 Randomised Trials of Statins. Lancet 366, 1267-1278.

Cangemi, C., Skov, V., Poulsen, M.K., Funder, J., Twal, W.O., Gall, M.A., Hjortdal, V., Jespersen, M.L., Kruse, T.A., Aagard, J., et al. (2011). Fibulin-1 is a marker for arterial extracellular matrix alterations in type 2 diabetes. Clin Chem 57, 1556-1565.

Chen, C., Kudo, M., Rutaganira, F., Takano, H., Lee, C., Atakilit, A., Robinett, K.S., Uede, T., Wolters, P.J., Shokat, K.M., et al. (2012). Integrin alpha9beta1 in airway smooth muscle suppresses exaggerated airway narrowing. J Clin Invest 122, 2916-2927.

Chen, P.Y., Qin, L., Li, G., Tellides, G., and Simons, M. (2016). Smooth muscle FGF/TGFbeta cross talk regulates atherosclerosis progression. EMBO molecular medicine 8, 712-728.

Cherepanova, O.A., Gomez, D., Shankman, L.S., Swiatlowska, P., Williams, J., Sarmento, O.F., Alencar, G.F., Hess, D.L., Bevard, M.H., Greene, E.S., et al. (2016). Activation of the pluripotency factor OCT4 in smooth muscle cells is atheroprotective. Nat Med 22, 657-665.

Chistiakov, D.A., Bobryshev, Y.V., and Orekhov, A.N. (2015). Changes in transcriptome of macrophages in atherosclerosis. J Cell Mol Med 19, 1163-1173.

Danussi, C., Petrucco, A., Wassermann, B., Pivetta, E., Modica, T.M., Del Bel Belluz, L., Colombatti, A., and Spessotto, P. (2011). EMILIN1-alpha4/alpha9 integrin interaction inhibits dermal fibroblast and keratinocyte proliferation. The Journal of cell biology 195, 131-145. 
1043

1044

1045

1046

1047

1048

1049

1050

1051

1052

1053

1054

1055

1056

1057

1058

1059

1060

1061

1062

1063

1064

1065

1066

1067

1068

1069

1070

1071

1072

1073

1074

1075

1076

1077

1078

1079

1080

1081

1082

1083

1084

1085

1086

1087

1088

1089

1090

Davis-Knowlton, J., Turner, J.E., Turner, A., Damian-Loring, S., Hagler, N., Henderson, T., Emery, I.F., Bond, K., Duarte, C.W., Vary, C.P.H., et al. (2019). Characterization of smooth muscle cells from human atherosclerotic lesions and their responses to Notch signaling. Lab Invest 99, 290-304.

Deford, P., Brown, K., Richards, R.L., King, A., Newburn, K., Westover, K., and Albig, A.R. (2016). MAGP2 controls Notch via interactions with RGD binding integrins: Identification of a novel ECMintegrin-Notch signaling axis. Exp Cell Res 341, 84-91.

Deloukas, P., Kanoni, S., Willenborg, C., Farrall, M., Assimes, T.L., Thompson, J.R., Ingelsson, E., Saleheen, D., Erdmann, J., Goldstein, B.A., et al. (2013). Large-scale association analysis identifies new risk loci for coronary artery disease. Nat Genet 45, 25-33.

Dobin, A., Davis, C.A., Schlesinger, F., Drenkow, J., Zaleski, C., Jha, S., Batut, P., Chaisson, M., and Gingeras, T.R. (2013). STAR: ultrafast universal RNA-seq aligner. Bioinformatics 29, 15-21.

Dzau, V.J., Braun-Dullaeus, R.C., and Sedding, D.G. (2002). Vascular proliferation and atherosclerosis: new perspectives and therapeutic strategies. Nat Med 8, 1249-1256.

Fukuda, D., Aikawa, E., Swirski, F.K., Novobrantseva, T.I., Kotelianski, V., Gorgun, C.Z., Chudnovskiy, A., Yamazaki, H., Croce, K., Weissleder, R., et al. (2012). Notch ligand delta-like 4 blockade attenuates atherosclerosis and metabolic disorders. Proc Natl Acad Sci U S A 109, E1868-1877.

Ghabrial, A.S., and Krasnow, M.A. (2006). Social interactions among epithelial cells during tracheal branching morphogenesis. Nature 441, 746-749.

Gilges, D., Vinit, M.A., Callebaut, I., Coulombel, L., Cacheux, V., Romeo, P.H., and Vigon, I. (2000). Polydom: a secreted protein with pentraxin, complement control protein, epidermal growth factor and von Willebrand factor A domains. Biochem J 352 Pt 1, 49-59.

Gupta, S.K., and Vlahakis, N.E. (2010). Integrin alpha9beta1: Unique signaling pathways reveal diverse biological roles. Cell Adh Migr 4, 194-198.

Hakkinen, L., Hildebrand, H.C., Berndt, A., Kosmehl, H., and Larjava, H. (2000). Immunolocalization of tenascin-C, alpha9 integrin subunit, and alphavbeta6 integrin during wound healing in human oral mucosa. J Histochem Cytochem 48, 985-998.

Hansson, G.K., and Klareskog, L. (2011). Pulling down the plug on atherosclerosis: cooling down the inflammasome. Nat Med 17, 790-791.

Hemani, G., Tilling, K., and Davey Smith, G. (2017). Orienting the causal relationship between imprecisely measured traits using GWAS summary data. PLoS Genet 13 , e1007081.

Hemani, G., Zheng, J., Elsworth, B., Wade, K.H., Haberland, V., Baird, D., Laurin, C., Burgess, S., Bowden, J., Langdon, R., et al. (2018). The MR-Base platform supports systematic causal inference across the human phenome. Elife 7.

Huang da, W., Sherman, B.T., and Lempicki, R.A. (2009). Systematic and integrative analysis of large gene lists using DAVID bioinformatics resources. Nature protocols 4, 44-57. 
1091

1092

1093

1094

1095

1096

1097

1098

1099

1100

1101

1102

1103

1104

1105

1106

1107

1108

1109

1110

1111

1112

1113

1114

1115

1116

1117

1118

1119

1120

1121

1122

1123

1124

1125

1126

1127

1128

1129

1130

1131

1132

1133

1134

1135

1136

1137

1138

Huang, X.Z., Wu, J.F., Ferrando, R., Lee, J.H., Wang, Y.L., Farese, R.V., Jr., and Sheppard, D. (2000). Fatal bilateral chylothorax in mice lacking the integrin alpha9beta1. Mol Cell Biol 20, 5208-5215.

Johnson, J.L. (2014). Emerging regulators of vascular smooth muscle cell function in the development and progression of atherosclerosis. Cardiovascular research 103, 452-460.

Kalluri, A.S., Vellarikkal, S.K., Edelman, E.R., Nguyen, L., Subramanian, A., Ellinor, P.T., Regev, A., Kathiresan, S., and Gupta, R.M. (2019). Single-Cell Analysis of the Normal Mouse Aorta Reveals Functionally Distinct Endothelial Cell Populations. Circulation 140, 147-163.

Kanayama, M., Kurotaki, D., Morimoto, J., Asano, T., Matsui, Y., Nakayama, Y., Saito, Y., Ito, K., Kimura, C., Iwasaki, N., et al. (2009). Alpha9 integrin and its ligands constitute critical joint microenvironments for development of autoimmune arthritis. J Immunol 182, 8015-8025.

Karpanen, T., Padberg, Y., van de Pavert, S.A., Dierkes, C., Morooka, N., Peterson-Maduro, J., van de Hoek, G., Adrian, M., Mochizuki, N., Sekiguchi, K., et al. (2017). An Evolutionarily Conserved Role for Polydom/Svep1 During Lymphatic Vessel Formation. Circulation research 120, 1263-1275.

Kessler T, Z.L., Liu Z, Yin X, Huang Y, Wang Y, Fu Y, Mayr M, Ge Q, Xu Q, Zhu Y, Wang X, Schmidt K, de Wit C, Erdmann J, Schunkert H, Aherrahrou Z, Kong W. (2015). ADAMTS-7 inhibits reendothelialization of injured arteries and promotes vascular remodeling through cleavage of thrombospondin-1. Circulation 131, 1191-1201.

Langley, S.R., Willeit, K., Didangelos, A., Matic, L.P., Skroblin, P., Barallobre-Barreiro, J., Lengquist, M., Rungger, G., Kapustin, A., Kedenko, L., et al. (2017). Extracellular matrix proteomics identifies molecular signature of symptomatic carotid plaques. J Clin Invest 127, 1546-1560.

Levy, D., Ehret, G.B., Rice, K., Verwoert, G.C., Launer, L.J., Dehghan, A., Glazer, N.L., Morrison, A.C., Johnson, A.D., Aspelund, T., et al. (2009). Genome-wide association study of blood pressure and hypertension. Nat Genet 41, 677-687.

Liao, Y., Smyth, G.K., and Shi, W. (2014). featureCounts: an efficient general purpose program for assigning sequence reads to genomic features. Bioinformatics 30, 923-930.

Liu, B., Pjanic, M., Wang, T., Nguyen, T., Gloudemans, M., Rao, A., Castano, V.G., Nurnberg, S., Rader, D.J., Elwyn, S., et al. (2018). Genetic Regulatory Mechanisms of Smooth Muscle Cells Map to Coronary Artery Disease Risk Loci. Am J Hum Genet 103, 377-388.

Liu, R., Holik, A.Z., Su, S., Jansz, N., Chen, K., Leong, H.S., Blewitt, M.E., Asselin-Labat, M.L., Smyth, G.K., and Ritchie, M.E. (2015). Why weight? Modelling sample and observational level variability improves power in RNA-seq analyses. Nucleic Acids Res 43, e97.

Liu, X., and Ntambi, J.M. (2009). Atherosclerosis: keep your macrophages in shape. Nat Med 15, 13571358.

Loubery, S., Seum, C., Moraleda, A., Daeden, A., Furthauer, M., and Gonzalez-Gaitan, M. (2014). Uninflatable and Notch control the targeting of Sara endosomes during asymmetric division. Curr Biol $24,2142-2148$. 
Luo, W., and Brouwer, C. (2013). Pathview: an R/Bioconductor package for pathway-based data integration and visualization. Bioinformatics 29, 1830-1831.

Luo, W., Friedman, M.S., Shedden, K., Hankenson, K.D., and Woolf, P.J. (2009). GAGE: generally applicable gene set enrichment for pathway analysis. BMC Bioinformatics 10, 161.

Marchler-Bauer, A., Lu, S., Anderson, J.B., Chitsaz, F., Derbyshire, M.K., DeWeese-Scott, C., Fong, J.H., Geer, L.Y., Geer, R.C., Gonzales, N.R., et al. (2011). CDD: a Conserved Domain Database for the functional annotation of proteins. Nucleic Acids Res 39, D225-229.

Misra, A., Feng, Z., Chandran, R.R., Kabir, I., Rotllan, N., Aryal, B., Sheikh, A.Q., Ding, L., Qin, L., Fernandez-Hernando, C., et al. (2018). Integrin beta3 regulates clonality and fate of smooth musclederived atherosclerotic plaque cells. Nature communications 9, 2073.

Mitchell, A.L., Attwood, T.K., Babbitt, P.C., Blum, M., Bork, P., Bridge, A., Brown, S.D., Chang, H.Y., El-Gebali, S., Fraser, M.I., et al. (2019). InterPro in 2019: improving coverage, classification and access to protein sequence annotations. Nucleic Acids Res 47, D351-D360.

Morooka, N., Futaki, S., Sato-Nishiuchi, R., Nishino, M., Totani, Y., Shimono, C., Nakano, I., Nakajima, H., Mochizuki, N., and Sekiguchi, K. (2017). Polydom Is an Extracellular Matrix Protein Involved in Lymphatic Vessel Remodeling. Circulation research 120, 1276-1288.

Mostovich, L.A., Prudnikova, T.Y., Kondratov, A.G., Loginova, D., Vavilov, P.V., Rykova, V.I., Sidorov, S.V., Pavlova, T.V., Kashuba, V.I., Zabarovsky, E.R., et al. (2011). Integrin alpha9 (ITGA9) expression and epigenetic silencing in human breast tumors. Cell Adh Migr 5, 395-401.

Nelson, C.P., Goel, A., Butterworth, A.S., Kanoni, S., Webb, T.R., Marouli, E., Zeng, L., Ntalla, I., Lai, F.Y., Hopewell, J.C., et al. (2017). Association analyses based on false discovery rate implicate new loci for coronary artery disease. Nat Genet 49, 1385-1391.

Nikpay, M., Goel, A., Won, H.H., Hall, L.M., Willenborg, C., Kanoni, S., Saleheen, D., Kyriakou, T., Nelson, C.P., Hopewell, J.C., et al. (2015). A comprehensive 1,000 Genomes-based genome-wide association meta-analysis of coronary artery disease. Nat Genet 47, 1121-1130.

Nishimichi, N., Higashikawa, F., Kinoh, H.H., Tateishi, Y., Matsuda, H., and Yokosaki, Y. (2009). Polymeric osteopontin employs integrin alpha9betal as a receptor and attracts neutrophils by presenting a de novo binding site. J Biol Chem 284, 14769-14776.

Patro, R., Duggal, G., Love, M.I., Irizarry, R.A., and Kingsford, C. (2017). Salmon provides fast and biasaware quantification of transcript expression. Nat Methods 14, 417-419.

Rader, D.J., and FitzGerald, G.A. (1998). State of the art: atherosclerosis in a limited edition. Nat Med 4, 899-900.

Randolph, G.J. (2013). Proliferating macrophages prevail in atherosclerosis. Nat Med 19, 1094-1095.

Ritchie, M.E., Phipson, B., Wu, D., Hu, Y., Law, C.W., Shi, W., and Smyth, G.K. (2015). limma powers differential expression analyses for RNA-sequencing and microarray studies. Nucleic Acids Res 43, e47. 
Robinson, M.D., McCarthy, D.J., and Smyth, G.K. (2010). edgeR: a Bioconductor package for differential expression analysis of digital gene expression data. Bioinformatics 26, 139-140.

Ross, R. (1996). Genetically modified mice as models of transplant atherosclerosis. Nat Med 2, 527-528.

Roy, S., Bingle, L., Marshall, J.F., Bass, R., Ellis, V., Speight, P.M., and Whawell, S.A. (2011). The role of alpha9betal integrin in modulating epithelial cell behaviour. J Oral Pathol Med 40, 755-761.

Samuelov, L., Li, Q., Bochner, R., Najor, N.A., Albrecht, L., Malchin, N., Goldsmith, T., Grafi-Cohen, M., Vodo, D., Fainberg, G., et al. (2017). SVEP1 plays a crucial role in epidermal differentiation. Exp Dermatol 26, 423-430.

Sato-Nishiuchi, R., Nakano, I., Ozawa, A., Sato, Y., Takeichi, M., Kiyozumi, D., Yamazaki, K., Yasunaga, T., Futaki, S., and Sekiguchi, K. (2012). Polydom/SVEP1 is a ligand for integrin alpha9beta1. J Biol Chem 287, 25615-25630.

Schreiber, T.D., Steinl, C., Essl, M., Abele, H., Geiger, K., Muller, C.A., Aicher, W.K., and Klein, G. (2009). The integrin alpha9betal on hematopoietic stem and progenitor cells: involvement in cell adhesion, proliferation and differentiation. Haematologica 94, 1493-1501.

Schunkert, H., Konig, I.R., Kathiresan, S., Reilly, M.P., Assimes, T.L., Holm, H., Preuss, M., Stewart, A.F., Barbalic, M., Gieger, C., et al. (2011). Large-scale association analysis identifies 13 new susceptibility loci for coronary artery disease. Nat Genet 43, 333-338.

Schweisguth, F. (2004). Regulation of notch signaling activity. Curr Biol 14, R129-138.

Shang, T., Yednock, T., and Issekutz, A.C. (1999). alpha9beta1 integrin is expressed on human neutrophils and contributes to neutrophil migration through human lung and synovial fibroblast barriers. J Leukoc Biol 66, 809-816.

Shankman, L.S., Gomez, D., Cherepanova, O.A., Salmon, M., Alencar, G.F., Haskins, R.M., Swiatlowska, P., Newman, A.A., Greene, E.S., Straub, A.C., et al. (2015). KLF4-dependent phenotypic modulation of smooth muscle cells has a key role in atherosclerotic plaque pathogenesis. Nat Med 21, 628-637.

Shur, I., Socher, R., Hameiri, M., Fried, A., and Benayahu, D. (2006). Molecular and cellular characterization of SEL-OB/SVEP1 in osteogenic cells in vivo and in vitro. J Cell Physiol 206, 420-427.

Smith, L.L., Cheung, H.K., Ling, L.E., Chen, J., Sheppard, D., Pytela, R., and Giachelli, C.M. (1996). Osteopontin $\mathrm{N}$-terminal domain contains a cryptic adhesive sequence recognized by alpha9beta 1 integrin. J Biol Chem 271, 28485-28491.

Sonnhammer, E.L., and Ostlund, G. (2015). InParanoid 8: orthology analysis between 273 proteomes, mostly eukaryotic. Nucleic Acids Res 43, D234-239.

Stitziel, N.O., Stirrups, K.E., Masca, N.G., Erdmann, J., Ferrario, P.G., Konig, I.R., Weeke, P.E., Webb, T.R., Auer, P.L., Schick, U.M., et al. (2016). Coding Variation in ANGPTL4, LPL, and SVEP1 and the Risk of Coronary Disease. N Engl J Med 374, 1134-1144. 
1235

1236

1237

1238

1239

1240

1241

1242

1243

1244

1245

1246

1247

1248

1249

1250

1251

1252

1253

1254

1255

1256

1257

1258

1259

1260

1261

1262

1263

1264

1265

1266

1267

1268

1269

1270

1271

1272

1273

1274

1275

1276

1277

1278

1279

1280

Sun, B.B., Maranville, J.C., Peters, J.E., Stacey, D., Staley, J.R., Blackshaw, J., Burgess, S., Jiang, T., Paige, E., Surendran, P., et al. (2018). Genomic atlas of the human plasma proteome. Nature 558, 73-79.

Sundstrom, J., and Vasan, R.S. (2006). Circulating biomarkers of extracellular matrix remodeling and risk of atherosclerotic events. Curr Opin Lipidol 17, 45-53.

Takeuchi, F., Isono, M., Katsuya, T., Yamamoto, K., Yokota, M., Sugiyama, T., Nabika, T., Fujioka, A., Ohnaka, K., Asano, H., et al. (2010). Blood pressure and hypertension are associated with 7 loci in the Japanese population. Circulation 121, 2302-2309.

van der Harst, P., and Verweij, N. (2018). Identification of 64 Novel Genetic Loci Provides an Expanded View on the Genetic Architecture of Coronary Artery Disease. Circulation research 122, 433-443.

Virella, G., and Lopes-Virella, M.F. (2003). Humoral immunity and atherosclerosis. Nat Med 9, 243-244; author reply 244-245.

Wang, L., Wang, S., and Li, W. (2012). RSeQC: quality control of RNA-seq experiments. Bioinformatics $28,2184-2185$.

Weber, C., and Noels, H. (2011). Atherosclerosis: current pathogenesis and therapeutic options. Nat Med $17,1410-1422$.

Wei Li, M.F., Sekhar P Reddy, Dae-Yeul Yu, Masayuki Yamamoto, Roy L Silverstein (2010). CD36 Participates in a Signaling Pathway That Regulates ROS Formation in Murine VSMCs. J Clin Invest 120, 3996-4006.

Weng, S., Zemany, L., Standley, K.N., Novack, D.V., La Regina, M., Bernal-Mizrachi, C., Coleman, T., and Semenkovich, C.F. (2003). Beta3 integrin deficiency promotes atherosclerosis and pulmonary inflammation in high-fat-fed, hyperlipidemic mice. Proc Natl Acad Sci U S A 100, 6730-6735.

Wirka, R.C., Wagh, D., Paik, D.T., Pjanic, M., Nguyen, T., Miller, C.L., Kundu, R., Nagao, M., Coller, J., Koyano, T.K., et al. (2019). Atheroprotective roles of smooth muscle cell phenotypic modulation and the TCF21 disease gene as revealed by single-cell analysis. Nat Med 25, 1280-1289.

Xie, G., Zhang, H., Du, G., Huang, Q., Liang, X., Ma, J., and Jiao, R. (2012). Uif, a large transmembrane protein with EGF-like repeats, can antagonize Notch signaling in Drosophila. PLoS One 7, e36362.

Young, E.P., and Stitziel, N.O. (2019). Capitalizing on Insights from Human Genetics to Identify Novel Therapeutic Targets for Coronary Artery Disease. Annu Rev Med 70, 19-32.

Zhang, L., and Ward, R.E.t. (2009). uninflatable encodes a novel ectodermal apical surface protein required for tracheal inflation in Drosophila. Dev Biol 336, 201-212.

Zhao, S., Guo, Y., Sheng, Q., and Shyr, Y. (2014). Advanced heat map and clustering analysis using heatmap3. Biomed Res Int 2014, 986048. 